\title{
Newspapers and Organizational Development: Management and Journalist Perceptions of Newsroom Cultural Change
}

\author{
Peter J. Gade
}

(C) 2004

By the ASSOCIATION FOR EdUCATION IN JOURNALISM AND Mass Communication

Peter J. Gade is an associate professor in the Gaylord College of Journalism and Mass Communication at the University of Oklahoma. The author thanks Keith P. Sanders and John C. Merrill for their wisdom and guidance throughout this research. Thanks also to Fred K. Beard for his thoughtful comments on an earlier draft of this manuscript.

Dedicated to my mother, Joan Beaton Callahan, (1932-2002). 


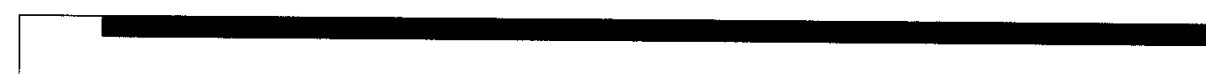




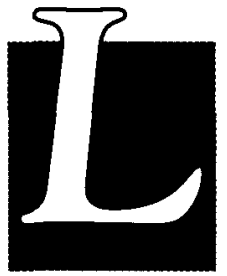

ess than a decade ago, there was a growing concern among corporate executives, scholars, and even many editors about the future of the newspaper industry. Newspapers faced stiff challenges on every horizon: circulation was stagnant, and a smaller percentage of the public was reading newspapers than at any time in the past half-century; the Internet was competing for the populace's time and advertisers' money; the costs of doing business were rising and unpredictable; and, for public companies, profit pressures were increasing as corporate managers sought to maintain control over their companies amidst waves of hostile buyouts and takeovers (Evans \& Wurster, 1997; Hirsch \& Thompson, 1994; Morton, 1998; Picard \& Brody, 1997; Whiteside, 1996). The message to those leading the industry was clear: change or fall victim to the forces redefining your environment.

There were also rumblings within the industry for change. Some influential editors and journalists became outspoken critics of how newspapers had lost sight of their public service mission and lost touch with their communities (Broder, 1990; Fallows, 1996; Kurtz, 1993; Merritt, 1996; Rosenstiel, 1993; Thames, 1998). These critiques often focused on the insular nature of journalism, emphasizing that journalists are "insider-oriented" elitists. This inner directedness could be understood in at least two ways: first, journalists tended to assess the value of their work in relation to how it is viewed by other journalists, not the public; second, working close to politicians and other powerful sources resulted in reporting more focused on power struggles and personal political battles than the issues that affect the daily lives of average citizens. Some editors - buoyed by support from scholars, a small body of research, and philanthropic organizations - became convinced that if journalists were able to get closer to readers, reconnect with their democratic mission, and begin framing stories from the center of their communities, then newspapers would reclaim their relevance (Lambeth, Meyer, \& Thorson, 1998; Merritt, 1996; Rosen, 1997; Smith, 1997).

It is within this framework that newspaper executives - addressing both internal and external issues - re-evaluated the goals and practices of the industry and set out to put it back on course. In 1994, the American Society 
of Newspaper Editors created a Change Committee, a group of editors given a 5-year period to develop and experiment with initiatives that would ensure the long-term viability of the industry. Founded on the heels of a recession that had lingered since the late 1980s and resulted in smaller newsroom staffs and budgets, the committee focused its attention on exploring ways to: (1) reorganize newsrooms for better efficiency and (2) realign journalists' values more closely with those of readers and citizens (McGuire, 1994).

Change initiatives emerged that attempted to transform the culture of the newsroom, making it more externally focused on markets and readers, while internally changing the nature of work by abandoning the century-old beat system of news coverage and replacing it with collaborative teams (Albers, 1995; Coyle, 1998; Haswell, 1995; Rappleye, 1998; Stepp, 1995a, 2000). "Change" became the mantra of many leading editors and executives, and the new, restructured approach to producing newspapers was labeled "strategic," "reader-driven," or "market-driven" journalism (Bedal, 1995). Newsroom managers, recognizing that they lacked the organizational background to plan, execute, and monitor fundamental change, increasingly looked to outside consultants to guide their efforts and alleviate employee resistance (Shepard, 1996, 1998). The process of change, seldom easy in any organization, became a target of skepticism for journalists, who worried that initiatives jeopardized core journalism values and credibility (Hickey, 1998; Stepp, 1995b; Underwood, 1998; Woo, 1998).

Organizational development (OD) is the study of how organizations evolve, learn, and adapt. This line of inquiry is well suited, although it has been rarely used, to explore and understand the process of change in the newspaper industry. The research reported in this monograph uses OD theory as a framework for assessing the perceptions and attitudes that top newsroom managers and rank-and-file journalists have about initiatives aimed at changing the newsroom culture. This study also explores the impact of two newer, largely unstudied variables that have been a part of change initiatives - newsroom restucturing and the reader-oriented redefinition of news values - to better understand how journalists perceive change and its impact.

Organizational development scholarship is rooted in social psychology and management. OD scholars concede that because organizations vary in size and resources and have different goals, OD research has generally focused on one organization at a time (Cameron \& Whetten, 1983). Argyris (1993) acknowledges that this situation-by-situation approach, which relies on on-site observations, in-depth interviews, and situation-specific variables, makes the task of generalizing results and theory building more difficult.

This study takes a different approach than most OD research and attempts to advance $O D$ theory building and the practical understanding of ongoing newspaper change by surveying a relatively large probability sample of rankand-file journalists and a census of top newsroom managers from 17 newspapers most experienced in ASNE-sanctioned change initiatives. The logic of the approach is that journalists working at newspapers that have experi- 
mented with similar change initiatives create a population of cohorts who have clear perceptions regarding change based on their common experiences. This commonality should permit valid research that extends beyond single organizations and site-specific variables, producing results that can benefit newsrooms embarking on change initiatives. Accordingly, this study extends newspaper change research by addressing the problem differently, both in terms of its theoretical framework and methodological design.

The extent to which change initiatives can be tied to economics is uncertain. By 2001, a recessionary national economy led the nation's largest public newspaper companies to downsize their workforces between 5 and $10 \%$ to maintain profit levels attractive to investors (Ridder et al., 2001). However, the late 1990s, a period of a strong economy and fast and furious change, saw the same high profits that had characterized the industry a decade earlier. Publicly owned companies, which account for nearly half the nation's daily circulation, returned an average profit of $20.7 \%$ in 1998 and $22.2 \%$ in 1999 (Morton, 1999, 2000). Advertising revenue was also at record levels, reaching $\$ 46.3$ billion in 1999 , the eighth consecutive year of record highs (Nicholson, 2000), casting doubt on prognosticators who only a halfdecade earlier had predicted the Internet would spell doom for newspapers.

\section{Literature Review}

Following the lead of the Change Committee and continuing today under the rubric of change, newsrooms are being reorganized, news values are being redefined, and the nature of newspaper journalism work is changing. The seriousness of prominent editors leading this effort can be understood by their numerous references to the need to "blow up" the newsroom and its associated routines and values (Peck, 1996; Stepp, 1995a; Weaver, 1998); another editor, using a less violent metaphor,

Following the lead of the Change Commillee and continuing loday under the rubric of change, newsrooms are being reorganized, news values are being redefined, and the: nature of newspaper journalism work is changing.

claims his goal for change is "cultural transformation" (Campbell, 1998). However, a large body of organizational development scholarship indicates that changing an organization's culture (its values and beliefs and form and function of work that supports them) is not easily accomplished, and understanding the need for change is not often enough to convince employees, and even members of management, to accept change (Argyris, 1993, 1974; Connor, 1992; Drucker, 1995; Gentry, 1996; Giles, 1991; Hirschhorn, 1991; Kanter, 1983).

Changing Organizational Structures. Following a national manufacturing trend, by the mid-1990s, newspaper managers began disassembling the assembly line, creating instead self-contained work teams (Shepard, 1998). The team-based structure flattened the traditional top-down manufacturing hierarchy, grouping editors and reporters into 6- to 10-member teams 
responsible for reporting, writing, editing, and packaging news in their coverage areas (Albers, 1995; Stepp, 1995a).

The most controversial changes have come in those newsrooms using cross-departmental teams (Rappleye, 1998). Section development teams at The Los Angeles Times include people from advertising, classified, editorial, marketing, and research. Former Times Publisher Mark Willes said these teams are necessary to create a stronger marketing consciousness at the newspaper. Journalists and scholars have questioned whether cross-departmental teams compromise the traditional "wall" between the news and business sides of news organizations. This controversy was fueled in October 1999 when the Times created a special Sunday magazine promoting the new downtown Staples Center. Written by journalists, the section garnered nearly $\$ 2$ million in advertising, which the paper split with the Staples Center (Strupp, 1999). Perhaps more indicative of the direction the industry is heading is that $63 \%$ of the editors responding to a 1999 Editor \& Publisher survey agreed that there should be more cooperation between news departments and business/marketing departments, while 29\% disagreed (Mitchell, 1999). Clearly, editors are becoming more active in marketing. A 1998 study found that $57 \%$ of the 192 newspapers surveyed have marketing teams that include editorial members (Coyle, 1998).

A less controversial change that none the less has had an impact on the nature of newspaper work has been the reorganization from a beat system to a team system of news coverage. Some of the reorganization plans of newspapers in this study are described briefly. After a year of planning, the St. Louis Post-Dispatch scrapped the beat system in 1999 for topic-driven teams. Staff had to reapply for jobs, 19 general assignment positions were redefined in the team structure, and editors became team leaders. Each team created a mission statement and set its goals (Shepard, 2000). At The (Columbia, S.C.) State, the news and features desks were abolished to facilitate a team structure. The paper also created an "office of the managing editor," which at any given time could be staffed by one of five different people (Stepp, 1995a). At many newspapers, changes in newsroom structure have brought with them new job titles that many news veterans would not recognize, including duty officer, maestro, circle editor, news manager of public life, and change facilitator.

At the Grand Forks (N.D.) Herald, editor Mike Jacobs said the change to reporting teams was initially resisted. He learned that change requires people in leadership positions who believe in change and are committed to executing it. To help staffers work through their problems with change initiatives, Jacobs brought in a marriage counselor to serve as "a listening post" between staff and upper management (Albers, 1995).

The Dayton (Ohio) Daily News adopted a "newsroom without walls" concept. Conceived by an architect, the reorganization eliminated departments and placed newsroom staff in gathering and producing teams. Managing editor Steven Sidlo said the model is "a system that breaches our walls of tradition, encouraging a more effective, fluid use of our resources" (Albers, 1995, p. 32). 
In Portland, The Oregonian's "warp-speed nine" initiative prompted managing editor Peter Bhatia to joke "Reorganization 'R' Us." More than $\mathbf{8 0}$ jobs were posted in the newsroom as open assignments. Nearly every writer, regardless of experience or seniority, had to reapply. The final result was 10 teams, with a flattened newsroom hierarchy that saw former editors become team leaders. Bhatia, aware that the flattened hierarchy offers fewer career advancement opportunities, said, "The satisfaction that people will get from this system is in the quality of their work and what they put in the paper as compared to a traditional career path" (Albers, 1995, p. 34).

Flattened newsroom hierarchies have resulted in some editors returning to the reporting ranks. In Tacoma, Wash., editor David Zeeck's reorganization of The News Tribune resulted in $34 \%$ of his staff changing jobs, and $23 \%$ of the editors becoming

In Portland. The: Oregonion's "warpspeed nine:" iniliative prompted managing editor Peter Hhatia lo joke " Reorganizalion 'R' I is." More than 80 jobs were posted in the newsroom as open assignments. Noarly every writer. regardless of experience or semiority had lo reapply. reporters (Haswell, 1995). At the Wichita (Kan.) Eagle, the copy desk was eliminated in 1995 and copy editors were assigned to reporting teams. Former managing editor Janet Weaver said "blowing up the copy desk" resulted in eight more staff reporters (Haswell, 1995). Weaver (1998) said the reorganization took the Eagle from a six-tiered hierarchy to just three tiers: editor, managing editor, and three equal teams - content, organization, and presentation. Stepp (1995a) writes the goal behind eliminating the editors at many papers was not only to cut payroll, but to simplify chains of command and reduce the number of news managers resistant to change.

Changing News Values. Aware that their readership is stagnant and influence declining, newspaper managers and journalists have been reexamining their news values. This introspection has manifested itself in several ways: an increased marketing consciousness, a desire for more credibility, the involvement of readers in deciding news and how it should be reported, and a sense the media are failing to live up to their historic democratic role of informing people of issues important to successful governance.

American Journalism Review, in a 2000 cover story titled "Reader Friendly," reported that the emerging culture of restructured newsrooms around the country is characterized by:

-enthroning readers as the "invisible giants," elevating them to near equal partners in decision making;

-erring on the side of caution rather than aggressiveness, rejecting stories that might offend readers as lacking compassion or sensitivity;

- promoting cooperation with everyone, from City Hall to the 
The long-time taboo of "pandering" to readers has been swept away by an attempt to reverse what some editors have called a "disconnection" between newspapers and the public. Following a series of meetings called the Journalism Values Institute in which 30 editors from around the country debated the problems of the industry, Peck (1996) wrote, "The essence of these evaluations comes down to this: American journalists continue to say they practice good journalism in the public's interest - but the public doesn't believe we deliver" (p. 5). Editors left the meetings agreeing that newspaper content includes too much gossip, not enough substance, bias but no balance, and a preoccupation with conflict and few solutions. The Oregonian's Bhatia summed up the problems: "Our comfort zones are painting the world in black and white. And our comfort zones are seeing the traditional good side and evil side of whatever issue it might be. We've got to blow that up" (p. 13).

Many of the editors most active in the ASNE Change Committee borrowed ideas from and adopted the language of civic (or public) journalism. Civic journalism broadens the concept of journalistic social responsibility into a more active role, with the goal of journalism becoming a catalyst for the revival of civic life by promoting citizen engagement and dialogue (Rosen \& Merritt, 1994). Merritt (1996) insists the practice of civic journalism requires journalists to abandon several common and traditional practices, including: valuing conflict as the primary narrative device, framing issues at extremes, maintaining an adversarial role with institutions, treating the readers as audiences rather than participants, and insisting that journalism credibility arises from detachment.

Stepp (2000) wrote that a cross-country tour of newsrooms left him impressed by how many newsrooms were using the language and techniques of civic journalism. He notes that when he raised this issue many editors and journalists dismissed it, suggesting civic journalism is a project-driven formula that they don't understand. Stepp, however, concluded: "Perhaps the resistance to the civic journalism label simply underlines how much some of the techniques have seeped into the newsroom groundwater" (p. 29).

Changing the Newsroom Culture. Nearly all editors who have involved their newsrooms in change initiatives have suggested the key to making change work is to create a new culture. Weaver (1998) said changing the newsroom culture requires "getting the staff to think of the whole paper, as opposed to their own story or small piece they contributed." She said that reporters need to be trained to work in a new system, as many lack the editing, headline writing, and design skills required in the team structure. Managers, too, have more pressure, as the staff is often competing for the attention of fewer bosses. And, because of the changing nature of journalism work, job performance evaluations need revision to reflect the standards and goals of a new system. She admits that "newsroom stars" under the old system often feel stifled by the team structure. Teams require a "new breed" of journalist with different personality traits and skills than the "lone wolf" who worked 
well alone and often produced breakthrough stories.

Sue Deans (1998), editor of The (Myrtle Beach, S.C.) Sun News, said for change initiatives to work staff members need to understand that change is a constant; it will not go away after a short time or a few experiments. The two "core issues" of change are continuous product improvement, and keeping aware of what readers want and the market demands. She said changing the newsroom culture requires emphasizing "passion" for the newspaper business and:

-impressing on people who do not want change that they must change or leave;

-eliminating "silo" thinking by creating cross-departmental approaches to work and evaluating work quality;

-staying focused on strategy and on the market.

Campbell (1998), who resigned in April 2000 as St. Louis Post-Dispatch editor after a stormy $31 / 2$ years, had embarked on an ambitious attempt at "cultural transformation" at the paper. He claims the existing newsroom "judgmental culture" is part of the problem with American journalism, and he attempted to change the Post-Dispatch's culture from one based on "judgmentalism" to one based on "collaboration."

By the millennium, the ideas for change that began in a couple dozen newsrooms in the mid-1990s were becoming the industry norm. Stepp (2000) wrote:

"From civic journalism to New Directions for News, from credibility reforms to the Committee of Concerned Journalists, a host of foundations, trade groups and other forces have been pouring millions of dollars into attempts to remodel how journalists think and act" (p. 24).

Impact of Change on Morale. Change initiatives have required journalists to rethink some fundamental principles of their work: their sense of news, audience, organization, and even the purpose of journalism. Signs of eroding morale were present before change began in the mid-1990s (Peck, 1991; Weaver \& Wilhoit, 1996), and morale problems in relation to change initiatives have been reported in trade journals (Oring \& Danko, 1995; Stepp, 1995b; Underwood, 1998).

Columbia Journalism Review, in a 2001 cover story, reported that its national survey found $\mathbf{8 4} \%$ of the responding journalists indicate that low morale is widespread in their newsrooms (Hickey, 2001). This finding is supported by a 2001 ASNE study that found $54 \%$ of the respondents saying they weren't sure if they would remain in the newspaper business 
(Cunningham, 2001). Among the reasons for low morale: ineffective leadership, management and editors who don't listen, not enough opportunity to be creative, and increasing budget pressures that arise from the drive to maintain high profits (Hickey, pp. 37-39).

Underwood (1998) wrote that the mid-1990s layoffs and a widespread belief that management used downsizing as a way of getting rid of unhappy journalists - many of whom were aggressive, good journalists in a traditional sense - have left "a deep and growing cultural divide between newsroom managers and their reporters" (p. 26). Many veteran reporters think that change initiatives - and associated reader-driven, marketing consciousness - made newspapers look needlessly desperate in the late 1990s when newspaper companies were posting record profits.

Stepp (1995b) wrote that changes in management goals may mark a historic period of journalism. Journalists always considered themselves bestowed by the First Amendment with special status, feeling they were public servants who value social responsibility; however, he writes, "You feel it in virtually every newsroom, the sag, the deflation, the suspicion that a special way of life is teetering" (pp. 15-16). The frustration is not limited to rank-and-file, but includes editors who face the challenge of leading changes they may not understand or support. Stepp (2000) wrote that editors are no longer seen by their staffs as in control of the newsroom, as publishers look for top editors who understand "a different approach" based on what the market needs and the reader wants. This leaves editors less time to focus on journalism and interact with their staffs, further widening the gulf between managers leading change and rank-and-file.

The Newspaper Association of America surveyed more than 2,600 newspaper journalists who left their jobs in the mid-1990s, trying to find the factors that caused journalists to leave the profession. The NAA found, beyond the expected reasons of stress and long hours, that people left newspapers because of low morale, lack of advancement, and perceived inequities in pay and promotions. The authors conclude all of these reasons are issues that management can control (Oring \& Danko, 1995).

Organizational Newspaper Research. In the past half-decade, a line of organizational newspaper research has looked at the impact of public ownership (companies that publicly trade stocks) on corporate goals and identifying the level of newspapers' market orientation (Beam, 1998, 2000, 2001; Hirsch \& Thompson, 1994; Martin, 1998; Picard \& Brody, 1997). This section reviews three areas of research that were relevant to the conception of this study: early organizational studies, the recent profit and marketorientation research, and the few attempts in recent years to study the process of managing change in the nation's newsrooms.

Breed (1955) and Argyris (1974) were pioneers in newspaper industry organizational research. Breed, a sociologist, suggested that role theory provides a model that explains the organizational relationships in newsrooms. He asserted that all newspapers, whether management and journalists admit it or not, operate under the influence of a publisher policy. The publisher, as a representative of ownership, has the authority to set and 
enforce the policy. Journalists learn the policy, which is often covert because it betrays journalistic values, through experience and observation. The social norms and conventions of the newsroom teach journalists how and when to conform or deviate from the policy. Breed concluded:

Thus the cultural patterns of the newsroom produce results insufficient for wider democratic needs. Any important change toward a more 'free and responsible press' must stem from the various pressures on the publisher, who epitomizes the policy making and coordinating role (p. 355).

Argyris (1974), an organizational development scholar, studied one of the nation's largest newspapers for $31 / 2$ years, exploring the paper's internal dynamics and how they related to problems of press credibility. He also provided the paper an organizational development program and advised during its implementation. In his book, Behind the Front Page, he concluded the internal system at the paper helped create policy clashes, one-upmanship among reporters, and fear of authoritarian bosses. He found the greatest resistance to new ideas came from mid-level editors and managers, who, despite acknowledging the need to change, would not participate in organizational efforts at change. Discussing his frustration about why the problems his systems analysis identified were not addressed, he wrote:

The reason is not (italics Argyris) a lack of motivation to solve them on the part of top management. The problems will not be solved because the individuals and groups behave in ways that create a living system which teaches them (they become acculturated) to be hard of hearing, to be unable and unwilling to take action on threatening issues (p. 243).

Gassaway (1984) used observation and survey to study the social construction of a journalist's reality. He found news judgment decisions were most often the result of "preordained news," determined by coverage beats and how editors decide to use their resources. Editors and reporters struggle for control of information because they often disagree on what should be communicated to the public. Editors' authority is derived from organizational hierarchies, but reporters can deny editors' authority by controlling information obtained in newsgathering. Gassaway concluded editors and reporters negotiate for control to prevent confrontations and reduce resorting to power.

Jeffers and Lewis (1989) studied organizational communication at a midsized newspaper and found rank-and-file journalists perceived their communication with their immediate supervisor and publisher as poor. They suggested the organizational climate could be improved by increasing the amount and frequency of communication at all levels. The authors concluded their study supported the findings of Pincuss, Knipp, and Rayfield 
(1988), who found rank-and-file employees' communication relationship with their immediate supervisor is a predictor of job satisfaction; however, employees' sense of having meaningful communication with top-level managers was as strong a predictor of satisfaction as immediate-supervisor communication.

In the mid-1990s, several scholars began to assess organizational structure and goals, often considering profit motive and its impact on normative journalism values. Demers (1996) integrated organizational and economic theory in his book, The Menace of the Corporate Newspaper: Fact or Fiction?, to define the corporate newspaper, its characteristics, and organizational dynamics. Demers asserted that corporate newspapers are complex bureaucracies controlled by trained managers, not owners. These managers are best understood as innovative professionals or "technocrats" who are more interested in professional, organizational, and technical goals than profit goals. Demers juxtaposed the roles of managers to those of owners, defining the latter as "capitalists" most interested in returns on their investments. In the 20th century, managers replaced owners as the driving force in corporations because the organizations had become complex bureaucracies that required professional management. Further aiding the transition was the death of the original owners, whose influence was dispersed over time and divided among heirs. Demers wrote the result is that corporate newspapers are efficiently managed and structured to maximize profits, but they place less emphasis on profit than non-corporate newspapers, which tend to be family-owned, less bureaucratic organizations. In two studies, his results indicate that newspapers become more rigorous editorially as they become larger, more complex organizations.

In studies that both support and refute Demers' work, Beam (1998, 2000, 2001) studied the conditions that influence newspapers' market orientation and whether market orientation affects content. To define and measure market orientation, Beam (1998) explored the extent that newspapers: (1) have one or more departments active in understanding customer needs and the factors affecting the needs, (2) share this information across departments, and (3) have various departments engaged in meeting select customer needs. He found that ownership by a large group is the most important predictor of a newspaper's market orientation, suggesting the corporate parent may not be involved in specific content decisions but is more likely to require certain general processes be followed in making content decisions. He concluded that traditional journalistic values are important at market-oriented papers, and while more market-oriented newsrooms are more committed to special interest and visual content, they are not less committed to traditional content, including public affairs. Beam (2000) has also found that newspapers that are 
part of privately owned companies are more market oriented than those of public companies. Using his survey data, Beam (2001) then chose 10 newspapers for a content analysis -5 papers with strong market orientation and 5 papers with weak market orientation. He found the majority of items on page one of both orientations was "public sphere" content, which includes government affairs; however, the percentage of public sphere items on page one for weak market orientation newspapers was significantly higher $(65.6 \%)$ than for strong market orientation papers $(54.9 \%)$. Overall, Beam analyzed the display pages (section front or topic lead page) and found papers with strong market orientation have proportionately more items devoted to private life, coping, and sports, while proportionately fewer items about government and public life.

Martin (1998) compared profits earned by 15 public newspaper companies to profits of publishing companies and yields from corporate and government bonds over an 11-year period (1984-1994). For the entire period, newspaper profits averaged $90 \%$ higher than publishing companies, $78 \%$ higher than government bond yields, and $54 \%$ higher than interest payments from corporate bonds. Using a scale created by an economist that labels profits $\mathbf{5 0 \%}$ above those of comparable measures as "excessive," Martin found that in 23 of 33 annual comparative indices (70\%) the newspaper companies in the sample earned excessive profits. In some cases, these excessive comparative profits occurred in the early 1990s during what an analyst called "the biggest advertising recession since World War II" (p. 512).

After newspapers embarked on broad, and in some cases bold, change initiatives in the 1990s, a few researchers began to study these initiatives through the lens of organizational development. Gentry (1993) observed while a small California daily embarked on several change initiatives aimed at better aligning its content with community interests. The year-long efforts, orchestrated by New Directions for News, led Gentry to conclude the following elements were essential for successful newspaper organizational change: (1) strong leadership; (2) management communication about: why change is needed, management's vision, and new performance standards; ( 3 ) staff involvement in the change process; (4) management rewarding correct behavior and extinguishing improper behavior; and (5) anticipating problems of acceptance and implementation. Working a few years later with the American Press Institute, Gentry (1996) developed a model he calls "A Roadmap for Change" that added several variables, including: (1) prechange analysis of the current culture to determine the extent and types of changes needed; (2) use of mission statements to clarify core values for employees; (3) flexible management strategies and putting people in the proper roles to execute them; (4) enabling structures, such as job training; and (5) creating visible symbols of the new culture. Testing the model, Gentry (1997) surveyed management and rank-and-file at six newspapers and found management thought it was doing a better job than the staff thought it was doing on all 10 elements of change the study addressed.

In a longitudinal case study, Gade and Perry (2000, 2003) measured newsroom employees' perceptions of change initiatives led by editor Cole 
Campbell from 1996-2000 at the St. Louis Post-Dispatch. Over 4 years, Campbell, known as an industry innovator, had some success making news values more reader driven, but the 1999 reorganization of newsroom coverage from beats to teams left much of the staff confused about their roles and job responsibilities. Campbell's embrace of public journalism did not resonate with a majority of the staff. Morale declined and was lowest among respondents with management duties. Respondents consistently

Camplsell's embrace of public journalism did not resomale: with a majority of the stall. Morale declined and was lowest among respondents with management duties. indicated they were open minded toward change until after reorganization, which apparently was the last straw in a series of changes that underscored Campbell's tenure as editor the resigned under pressure in April 2000). Over the course of the study, respondents consistently indicated that they failed to see how change initiatives contributed to better journalism.

At a time when cross-departmental teams were still new to the industry, Sylvie (1996) studied how department heads of news, advertising, and circulation perceived their identity and ability to cooperate with each other. News managers named advertising as the most difficult department, while the advertising directors named the news editors as least cooperative. Newsroom managers were the only department heads not to rank their respective department's concerns as most important, ranking circulation success the most important. News editors showed a significantly greater tendency to say more cooperation between departments is needed. Sylvie concluded the news managers exhibit a "surprising sensitivity" to marketoriented concepts, which gives credibility to journalists' anecdotal claims that the newspaper industry is moving toward a greater market orientation.

A meager amount of research exists on newspaper team performance. Russial (1997) studied changes in health and science content at The Oregonian after that paper created a Health and Science team. He found that the team produced more coverage that received better play (A1 or Metro section front) than before the team was created. Russial suggested that although his study did not measure coverage quality, the creation of a team-based system represents a realignment in the use of newsroom resources that may have important consequences on news content.

Neuzil, Hansen, and Ward (1999) surveyed Minneapolis Star Tribune and St. Paul Pioneer Press journalists working in teams and found most thought they had less authority and less success getting story ideas in the paper than before teams were created. Those who thought they had less authority also said they were unsure of the chain of command, worked on larger teams, and were reporters more than editors. The researchers concluded if a goal of team work was to "empower" journalists by granting them more autonomy to be innovative, this goal was not being met.

In sum, trade journals and a developing body of research provide evidence 
that newspapers are changing in some fundamental ways: flattening organizational structures, replacing traditional beats with teams, revising job descriptions and required skills, rethinking organizational values, and redefining news judgment.

Using Organizational Theory to Make Sense of Change. The study of "organizations" is a relatively new discipline. Drucker (1995) wrote that "no one in the United States - or anyplace else - talked of 'organizations' until after World War II" (p. 85). Drucker said that the modern idea of an organization - as a purposely designed and specialized entity that is defined by its task and is distinct from society's other institutions - emerged in the second half of the 20th century with what he calls the "management revolution." Initial theoretical assumptions of this revolution were largely shaped by turn-of-the-century scholars: Taylor's views on "scientific management" and Weber's ideas on the rational and specialized bureaucracy. This organizational model is characterized by a hierarchical division of labor where managers are the "thinkers" and laborers are the "doers" (Senge, 1990). Employees develop highly specialized skills that increase performance and productivity, while management's job is to ensure the conditions exist for the organizational "machine" to run smoothly. Recognizing that organizations must evolve and adapt to survive in changing environments, Lewin (1947) suggested a "natural" (as opposed to mechanical) metaphor to explain organizational dynamics; change, he wrote, can be best understood and managed through a process of "unfreeze, change, refreeze." These early attempts to understand organizations and their dynamics prepared the intellectual soil for the growth of organizational development, which attracted the interest of U.S. scholars and corporate managers in the last quarter of the 20th century as the changing global marketplace threatened U.S. dominance (Bergquist, 1993; Drucker, 1995; Kanter, 1983; Senge, 1990).

Although Taylor's and Weber's (and to a lesser extent Lewin's) ideas are considered outdated, they have proven resilient and modest adaptations of them are still very much alive in both theory and practice. Bergquist (1993) wrote that most organizational theorists have conceived organizations as pendulum-like mechanisms, which value "simplicity in motion" and homeostasis. When organizations experience turbulent times, they tend to seek equilibrium by returning to their previous form and function. However, the structured and predictable environment in which U.S. companies once thrived no longer exists, and Bergquist contends a more accurate metaphor in the postmodern world is that of the organization as a liquid, "poised on the edge of order and chaos" (p. 9). The liquid system, he wrote, contains at the same time both elements of stability and change, especially along the edges, or shifting boundaries. In an organizational sense, it is the shifting boundaries that offer potential for understanding the change process. It is these places on the "edge" where innovation occurs and where organizational traits such as mission, communication, and leadership become integral to success.

In perhaps the seminal book on organizational change and development, Kanter (1983) wrote American companies that value "innovation" are better 
placed to use their employees' creative capacities and stay ahead in changing environments. Interviews with 65 corporate executives led Kanter to conclude the innovative companies are integrated (my italics); they grant power to individuals to encourage fresh thinking and create opportunities for new ideas to cross organizational boundaries. She juxtaposed integrated companies with "segmented" companies, which are characterized by an "overspecification" of resources and consider themselves successful when every segment works well independently, without much need for communication. Segmented companies, Kanter wrote, seek stasis, because they are constantly looking to the past to define the future; accordingly, habits and routines that maintain the course are valued.

Kanter identified five major building blocks in change initiatives that increase the company's capacity to meet new challenges (p. 290):

1. Departures from tradition: activities or ideas that require the organization to think and behave in new ways.

2. Crisis or galvanizing event: a critical event that cannot be solved by traditional means. This allows a non-traditional idea to be pushed forward.

3. Strategic decisions: the opportunity for management to create a vision by articulating a deliberate and conscious direction.

4. Individual "prime movers": people who push the innovative strategy through the organization by communicating strategic decisions and manipulating the symbols of the organizational culture toward the direction of change.

5. Action vehicles: mechanisms that allow new action. These include training programs, successful results for people using new practices, new organizational rewards that support new practices, and ongoing messages of the benefits experienced by individuals using the new practices.

Kanter wrote: llat managers need three new sets of skills to operale effectively in integrated, innovative environments: "power skills" used to persuade olhers to invest in new initiatives: ability to manage problems associaled wilh teams and grealer employee participation; and understanding of how orgatnizational change is designed and constructed.

Kanter wrote that managers need three new sets of skills to operate effectively in integrated, innovative environments: "power skills" used to persuade others to invest in new initiatives; ability to manage problems associated with teams and greater employee participation; and understanding of how organizational change is designed and constructed. She concluded that "the art and architecture of change" requires managers to abandon their reliance on traditional analytical tools, which measure what already exists or has occurred. "Change 
efforts have to mobilize people around what is not yet known, not yet experienced ... they require a leap of faith that cannot be eliminated by presentation of all the forecasts, figures, and advance guarantees that can be accumulated" (p. 304). Accordingly, the paradox of managing change, she wrote, is "there needs to be a plan, and the plan has to acknowledge that it will be departed from" (p. 305).

Most attempts at organizational development involve efforts to transform an organization's culture. Schneider, Brief, and Guzzo (1996) wrote that the values and beliefs that are the foundation of an organization's culture can be changed by focusing on the tangible things - such as practices, policies, and procedures - that define daily life in the organization. It is these tangible phenomena that comprise an organization's climate, and for real cultural change to occur, management must change the climate in which the employees exist. The authors contend that many efforts at cultural change are focused on "macro" issues such as values and beliefs, while overlooking the more tangible issues that create the organizational climate in which employees experience everyday life. They wrote: "Sustainable organizational change is most assured when both the climate - what the organization's members experience - and the culture - what the members believe the organization values - change" (p. 9).

Successful companies have increasingly educated workforces, and they are creating cultures that are more innovative and flexible (Fisher, 2000). The new, desired culture is one in which power and accountability are shared between managers and employees in a manner that allows companies to respond quickly to challenges and opportunities. The goal of these efforts is to unleash and channel the power of employees' knowledge in an organizational "culture of contribution." Fisher acknowledges that this is a major cultural shift for most U.S. companies because - unlike the Japanese, whose collective society adapted easily to a team-building, egalitarian corporate model - "America's professional workers value their individualism and often express it in counterproductive ways" (p. 48). Corporate America also clings to some values that work against creating a culture of contribution; most prominent among these, Fisher wrote, is the corporate view on job attachment. Workers are expected to accept such surprises as downsizing, job reclassification, or relocation with quiet stoicism, which contradicts companies' claims they are striving to empower employees as co-partners with management. Fisher contends that U.S. managers need to be aware that there is no single ideal corporate culture; rather, corporate culture is better understood as a combination of macro and micro cultures. Many senior managers claim to embrace a culture of contribution, but Fisher contends that few have ideas about how to put a program or process in place to let the transformation occur. On the other hand, the changing nature of professional work, driven by new technology, has organizations acting as though they are horizontally constructed even though most corporate organizational charts still reflect a vertical hierarchy. If management is to be successful creating the culture of contribution, it must cede some of its "span of control" and forge a "span of relationships," with workers and managers acting more as 
"learners than knowers, listeners than tellers, partners than adversaries" (p. 50). Fisher cautions that management should not be too optimistic that a reorganization into teams will solve the ills of the company; rather, a culture of contribution is more likely to develop in a climate where workers are trusted and have the freedom to think and act like owners.

At the core of many organizational development efforts over the past two decades has been the restructuring of organizations from vertical hierarchies into more horizontal, "flattened" designs where most of the work is done by self-directed teams. In theory, teams "empower" employees by giving team members more decision-making authority and eliminating vertical chains of command. However, empowerment efforts not only require management to share power, they also demand that individual team members think differently about the nature of work. Labianca, Gray, and Brass (2000) found that empowerment efforts require a change in "schemas" - cognitive frameworks that give meaning to experience - for both management and lower level employees. The authors analyzed a 2-year organizational development project involving team building and increased participation of lower level employees in decision making. Before the project, the "schema-in-use" for organizational decision making was that management should maintain control of events and decision making, and this schema was understood by both management and employees. The expected new schema for management included: making the organization more team oriented and collaborative, empowering lower level employees, aligning organizational structure effectively, and keeping current workers. For the rank-and-file, the expected new schema was characterized by working on team building, creating more avenues of communication, and encouraging employees to air their "beefs." The authors found: a great amount of employee skepticism at the outset about the likelihood of real change; despite a series of organization-wide meetings, interviews revealed both managers and nonmanagers were unclear about the project's goals; resistance was heightened when managerial behavior failed to conform with its stated expectations; and management incorrectly assumed that employees would postpone judgment of the reorganization plan until after it was implemented. The authors concluded that employees' resistance to the empowerment plan was motivated less by intentional self-interest than by constraints of well-established, ingrained schema.

Randolph (2000) wrote that few managers or employees fully understand how empowerment affects traditional patterns of corporate hierarchy and behavior. Management confuses empowerment as "giving people the power to make decisions," and this perception misses the essential notion of empowerment, that a great amount of power already exists in employees' knowledge, experience, and motivation. Rank-and-file perceive empowerment to mean they will be given the freedom to make all major decisions about their jobs. Randolph wrote that empowerment efforts do require a cultural shift; however, the shift is from one person making decisions to team-based shared decision making. He asserts that empowerment makes employees more accountable than the older, hierarchical culture, and it is 
best understood as a strange combination of opportunity and risk. An organization moves toward team-based empowered culture through three stages: (1) starting and orienting the process of change, (2) making changes and dealing with discouragement, and (3) adopting and refining empowerment to fit the organization. Each stage utilizes three "interlocking tools" sharing information, creating autonomy through boundaries, and replacing the hierarchy with self-directed teams.

Hirschhorn (1991), a management scholar whose work focuses on teambased organizations, wrote that the entire philosophy of management is changing as corporations flatten hierarchies and adopt new team environments. Successful managers develop roles for team members and "manage the boundary," communicating the company's needs to the team and the team's needs to the company. Managers lead by creating a structure in which the team can be successful and by positioning themselves to defend the team's efforts. Managers must realize they are both cause of and solution to many team problems. To be successful, managers must show their vulnerability (a traditional management faux pas) and willingness to learn from team members. Exhibiting these traits shows that managers are open to new ways to solve problems and encourages team members to respond to challenges that can enhance team performance.

Although development efforts are characterized by dispersing power throughout an organiza-

Effective leaders need to: articulate a vision of the future: create svmbolic: impressions to communicate the vision: build networks; empower followers: make choices (often painful ones): and keep perspectives of the followers based in reality.

tion, management's ability to provide leadership remains a key to organizational success. Kets de Vries (1993), a psychologist who focuses on the "psychodynamics of organizations," wrote that organizational culture depends on the psychological contract that exists between its leaders and followers. Effective leaders need to: articulate a vision of the future; create symbolic impressions to communicate the vision; build networks; empower followers; make choices (often painful ones); and keep perspectives of the followers based in reality. He wrote that the leader/follower relationship a process of social comparison that involves power, authority, hero worship, flattery, ambition, and attention seeking - provides tremendous opportunities for distorted management reasoning. The key is for managers to "preserve their hold on reality." Trust is essential for a healthy organization, and trust is dependent upon communication, support, respect, fairness, competence, and consistency on the part of the leaders. He concluded, "In order for the leader to understand the meaning of these words, it is important that he or she realize what it means to be a follower, how it feels to be in that position" (p. 176).

The importance of communication in organizations, especially during times of change, has spawned its own discipline of study. Lewis (1999) wrote 
that a growing body of empirical research indicates that the communication process and organizational change efforts are "inextricably linked processes" (p. 44). Communication plays an important role in several aspects of the change process, including: creating and articulating a vision; soliciting input and channeling feedback to and from all levels of the organizational hierarchy; and propelling and altering the paths of change (Cameron, Freeman, \& Mishra, 1993; Fairhurst, 1993; Rogers, 1995). The organizational communication literature reveals that communication has been shown to reduce uncertainty associated with change efforts (Eisenberg \& Riley, 1988; Lewis \& Seibold, 1998), increase accuracy in perceptions about the reasons and goals of change (Brown, 1991), and increase willingness to participate in planned change (Miller, Johnson, \& Grau, 1994).

Studying the methods and channels organizations use to communicate change, Lewis (1999) found change agents consider themselves to be the primary sources of change-related information, and they solicit input much less frequently than they disseminate information. She suggests that management's lack of use of channels of communication, especially upward channels, limits feedback from lower level employees who do the work of the organization. This approach can affect the success of change efforts, as "changes in status, reward structures, job descriptions, roles, work methods, work relationships, and procedures bring significant organizational issues to the surface" that increase rank-and-file employees' need to communicate with their supervisors (p. 69).

There is a small body of literature on organizational attempts to initiate market-oriented cultural change. Narver and Slater (1990) described a market-oriented culture as one that most effectively and efficiently creates superior customer value. Harris (1998) defined a market-oriented culture as "the dominant, dynamic segment of an organization whose orientation, attitudes and actions are geared towards the market" (p. 360). Harris contends that most reseachers err when they assume an organization has a single, unitary culture. This approach ignores the dynamic interaction of many aspects of an organization's culture and denies the possibility of the existence of multiple cultures. Generally, developing a market-oriented culture can be understood as a means to improve organizational efficiency and effectiveness. However, Piercy (1997) maintains the success of developing such a culture is largely dependent on internal power relationships and organizational politics, which - at least in the short term - do not necessarily lead to high levels of organization-wide motivation, commitment, or satisfaction. When understood in this context, developing a marketoriented culture can be seen as one of many ways that an organization can impose cultural control over the attitudes, actions, and behaviors of its members. Overall, Harris and Ogbonna (2000) wrote that the literature on the effects of developing market-oriented cultures is inconsistent, with some studies suggesting that the new culture improves employee satisfaction and commitment and others indicating this is not the case. However, researchers tend to agree that the success of any attempt at creating a market-oriented culture is contingent on employees who have to implement it. In nearly all 
cases, this is the front-line employees who are the primary link between an organization and its customers. The authors also contend that developing a market-oriented culture should be concerned with the long-term generation of values, attitudes, and behaviors, but the underlying assumption of the market culture is continuing responsiveness to customer needs. The dilemma for organizations is how they can craft short-term responses to "increasingly fickle" customer needs in a manner that does not conflict with long-term organizational objectives. Harris and Ogbonna concluded that this condition is "a contradiction yet to be resolved or fully understood" (p. 336).

Change, because it requires giving up what is known and routine for something new that may not be understood, is often met with resistance. De Jager (2001) wrote that many managers perceive employees who resist change as a problem. He contends this a short-sighted view that fundamentally misunderstands the causes of resistance and the potential benefits resistance can exert on an organization. De Jager wrote that businesses today acknowledge the need to change, but there is so much change that employees become confused and see themselves pushed in conflicting directions. Management is wise to understand that resistance to change is a tool that can be used to guide an organization. "Another way of looking at resistance is as a gateway or filter. Resistance to change helps us select from all possible changes the one that is most appropriate to the current situation" (p. 24). Because change involves replacing old organizational routines and values with new ones, managers must be able to provide answers for employees to some fundamental questions:

1. Why is the old status quo no longer sufficient?

2. What will it cost to make the transition from the old to new ways of doing things? De Jager identified several likely costs: disruption of routines, training, temporary low morale, new hires, people leaving, and the emotional cost of destroying what was.

3. Is the cost of change justified by the incremental benefits of the change proposed?

4. Does the proposed change support and reinforce existing core values?

Summary. As the millennium approached, the newspaper industry faced imposing, concurrent challenges on several fronts: stagnant circulation and a slowly dwindling base of readers; a fragmenting mass media market; new electronic media that are changing the way people access and use information; threats to traditional sources of advertising; and unpredictable but rising costs of production. In the wake of a mid-1990s recession that saw significant cutbacks, layoffs, and downsizings, newsrooms were restructured and reorganized. Hierarchical newsroom designs were flattened, and the beat system of coverage centered on social institutions was replaced by a team system that defined coverage areas by topics believed of greater interest to readers and consumers. What becomes apparent from the industry trade journals is that "change" became the guiding light of the industry in the 
late 1990s. Feeling out of step with the social patterns and interests of the public, the industry questioned its news values and management has focused on changing the culture of the newsroom to include greater market-

In short. the challenge of conceiving and leading change falls on management, while rank-and-filt: areexpected to enact and embrace change: initiatives that affect many of their conventions and values. ing awareness and knowledge. Editors are increasingly taking on marketing duties, working in cross-departmental teams with advertising, circulation, and marketing directors to create strategies to attract readers, often in specific demographic groups that advertisers are willing to pay to reach. Rank-and-file journalists are expected to accept restructur-

ing, redefined news values, and a greater sensitivity to marketing as part of a larger cultural change process that is redefining their jobs and norms as journalists.

Organizational theory suggests that integrated organizations are more innovative and flexible and respond more quickly to opportunities and challenges. The basis of power and decision making in integrated organizations shifts from being solely in the hands of management to a shared arrangement that empowers employees to use their knowledge and skills in team-based systems. Teams, and their individual members, respond to more decision-making power and autonomy by taking more responsibility for the quality of their work and becoming more productive. Organizational change and development is understood as a process with several stages, including planning, executing, and monitoring the progress and results. Because organizations have different values and goals, the study of OD has usually focused on one organization at a time, identifying the impact of site-specific variables on organizational development. This approach, while making theory building more difficult, has, however, led to researchers identifying several variables that impact the success of $O D$ efforts. These variables include an organization having a clear mission, employees who understand the mission and organization's core values, effective organizational communication, employee participation in crafting and implementing change initiatives, strong leadership, trust, flexibility, and mechanisms that monitor the progress of change initiatives and reward desired behavior. The effect of successful OD efforts should be empowered employees who, in self-directed work teams, are more motivated, productive, and responsible for their work. In theory, at least, successful OD efforts should in the long term improve employee morale.

However, change is also understood as a difficult and risky process. It requires employees (both management and rank-and-file) to embrace new values, to alter routines, and to think differently about their organizational roles and the nature of their work. It requires greater accountability from empowered rank-and-file and a new, less autocratic style from management. Accordingly, resistance to change should be expected, and in some cases is 
rational. For management, successful OD includes understanding the reasons for resistance and having the flexibility to find ways of working through resistance.

In short, the challenge of conceiving and leading change falls on management, while rank-and-file are expected to enact and embrace change initiatives that affect many of their conventions and values. Management perceives it is initiating change in the best interests of the organization and industry, while rank-and-file ponder the reasons for change and are sensitive to how it is implemented. Organizational theory and change models provide conceptual guidelines that should help predict effective organizational development (OD) initiatives. Given the vast amount of change in the newspaper industry and the relative dearth of research studying these OD initiatives, this study of top newsroom managers and rank-and-file journalists at newspapers leading industry change explores the following research questions and tests three hypotheses.

RQ1: What are the attitudes and opinions of management and rank-and-file journalists toward organizational change?

RQ2: How do management and rank-and-file perceive the change process in relation to organizational development theory?

RQ3: How do management and rank-and-file perceive organizational change in relation to the normative values of journalism and marketing?

RQ4: Have change efforts affected rank-and-file perceptions of news values and organizational structure?

RQ5: Have change efforts affected rank-and-file morale?

RQ6: Does organization size (measured by circulation) affect how rank-and-file perceive change?

H1: Management will perceive it has done significantly better at organizational development than rank-and-file.

H2: Morale among rank-and-file will be low.

H3: Rank-and-file perceptions of organizational development will predict morale.

\section{Methods}

This study used two survey instruments: a 62-statement survey sent to a sample of rank-and-file at 17 newspapers that have been engaged in change initiatives and a 20-statement survey sent to a census of top newsroom managers at the same papers. The rank-and-file survey was designed to explore respondents' attitudes toward concepts important to all newspapers experimenting with change: news values, organizational structure, and morale. The survey included statements that allowed measuring the degree to which the newsroom change process has adhered to organizational development theory. There were also statements asking rank-and-file to assess the relationship of change with journalistic and marketing goals. The 20-statement management survey focused primarily on issues of organiza- 
tional development, asking managers to assess the change process and their leadership of it. These 20 statements also appeared on the rank-and-file survey, allowing for a comparison between managers and rank-and-file on issues important to successful organization development. On both surveys, respondents were asked to record their level of agreement or disagreement to stimulus statements along a 5-point Likert-like intensity scale.

Choosing the Newspapers. The intent was to generate a large enough number of respondents from a broad enough sample of newspapers (in terms of size, geographic location, types of ownership, and experience with change) to have results that are generalizable to newspapers implementing change. To ensure the newspapers in the sample were among those most experienced in change initiatives, the 1997 ASNE Change Committee annual report was used to draw a purposive sample. These newspapers had top managers who were members of the 1997 Change Committee, or the newspapers' experiments with change were discussed in the committee's annual report.

The publisher or a top news executive of all 17 U.S. newspapers active on the committee was contacted by telephone. Only two Change Committee papers declined involvement in the study: Chattanooga (Tenn.) Times and Charlotte (N.C.) Observer. The 15 papers that participated are (from smallest to largest circulation): Columbia Missourian; (DeKalb, Ill.) Daily Chronicle; The Missoulian (Mont.); Grand Forks (N.D.) Herald; Fredericksburg (Va.) Free Lance Star, Bakersfield Californian; Wichita (Kan.) Eagle; Honolulu Advertiser; The (Colorado Springs, Colo.) Gazette; The (Columbia, S.C.) State; The (Tacoma, Wash.) News Tribune; Dayton (Ohio) Daily News; San Jose Mercury News; The (Portland) Oregonian; and (Minneapolis) Star Tribune. It should be noted that the Columbia Missourian is staffed by students in the University of Missouri School of Journalism, and the rankand-file from this newspaper - because they are not professional journalists - were not included in the sample.

Three newspapers were added to the study: St. Louis Post-Dispatch; Kansas City Star; and The Los Angeles Times. The Post-Dispatch was chosen because its editor at the time, Cole Campbell, instituted sweeping changes focused on issues relevant to this study. The Kansas City Star was chosen because that paper was sold and restructured in the years immediately preceding the study, and its publisher, Arthur Brisbane, was the chair of the 1998 Change Committee. The Los Angeles Times was chosen because of its self-proclaimed desire to set an industry example of how to restructure a news organization into cross-departmental teams that are more marketing conscious. The additions created a sample of 18 newspapers with a circulation range from about 5,000 (Columbia Missourian) to more than 1 million (The Los Angeles Times). The papers come from 14 states, representing every major geographic region of the nation. At the time of the survey, newspapers from 11 companies were in the sample, including 9 newspaper groups or chains and 2 family-owned papers. Thirteen of the papers were owned by public companies (those that offer public stock), and 4 were private (Editor \& Publisher International Yearbook, 1997; Potter, 1998). 
Creating the Sample. Sixteen of the papers supplied the researcher with a list of newsroom employees. At the remaining paper, the San Jose Mercury News, a contact person worked with the researcher to identify top newsroom managers and draw a random sample of rank-and-file. To ensure a response from managers that would be large enough to allow for statistical comparison with rank-and-file data, a census of the top newsroom managers at each paper was included in the overall sample. Each paper was asked to identify its top newsroom managers or those people at the rank of department head, section editor, or team leader and above. These managers were chosen because they are responsible for creating or implementing and overseeing newsroom policies and procedures. At several papers, there were as few as a half-dozen people at these ranks or higher, and at some of the larger papers, there were more than a dozen managers in these positions.

The rank-and-file sample was determined by newspaper size. The first consideration was to have enough responses from the smaller papers for statistical analysis by organizational size. Accordingly, all rank-and-file at the four smaller papers (less than 50,000 circulation) were included in the sample ( $n=137)$. Overall, a sample was sought that would enable an approximate proportional representation of journalists for all three circulation strata. From the seven papers between 50,000 and 250,000 (the actual range is 71,000 to 156,000 ), a random sample of 1 of 3 newsroom employees was drawn from each newspaper $(n=259)$; from the six papers with more than 250,000 circulation, 1 of 5 newsroom employees was randomly selected ( $n=313$ ), except for The Los Angeles Times, where 1 of 10 employees was randomly selected $(\mathrm{n}=98)$.

A total of 989 surveys -182 to top managers and 807 to rank-and-file was mailed in May 1998. Following closely Dillman's Total Design Method (1978), a postcard was sent as a reminder to nonrespondents about 10 days after the first mailing; a complete survey packet was sent to nonrespondents about 3 weeks after the first mailing.

\section{Results}

Of 807 surveys sent to rank-and-file, 457 were completed and returned, a response rate of $56.6 \%$. The 182 surveys sent to top managers yielded 68 responses, or $37.3 \%$ (see Appendix 1 for a breakdown of the number sampled and returned by newspaper). The instrument sent to management had 20 statements, mostly about organizational development, that were also on the rank-and-file survey. This approach allowed for a comparison of management and rank-and-file responses. The lower response rate for management can be partially explained by the instrument; beyond the 20-statement survey, management was asked to complete a $Q$ study (not reported in this monograph). Comparative results are reported first, followed by rank-andfile data.

Management respondents' demographics:

-26 women, 42 men;

-1 African-American, 2 Asian-Americans, 2 Hispanics, 62 whites, 
and 1 indicated other;

- ages ranged from 26 to 59 , with a mean of 44.5 ;

- experience ranged from 3 to 38 years, with the mean 22.0 years.

Rank-and-file respondents' demographics:

- 177 females, 274 males, and 6 did not respond;

- 25 African-Americans, 19 Asian-Americans, 9 Hispanics, 2 Native Americans, 382 whites, and 20 indicated other or did not respond;

- ages ranged from 22 to 77 , with the mean 41.98;

- experience ranged from 1 to 60 years, with the mean 17.72 years;

- 272 indicated they had "no managerial duties," 181 said they had "some managerial duties," and 4 did not respond.

Variable Measures. Most of the 62 rank-and-file survey statements were written to probe change initiatives in relation to news values, organizational structure, organizational development, and morale. The statements exploring news values incorporate ideas from trade journals about the changing nature of news, but also reflect norms articulated in the Libertarian and Social Responsibility theories of the press (Altschull, 1995; Merrill, 1974; Schudson, 1995; Siebert, et al., 1956). The statements that construct the organizational structure variable were taken from trade journal and organizational development literature. The statements in the organizational development construct were all derived from the OD literature. Morale statements were written to explore both individual respondents' attitudes about their own morale and their perceptions of morale in the newsroom. Factor analysis of the rank-and-file data assisted construction of the four concepts: 14 statements measure news values (Cronbach's alpha $=.75$ ); 12 statements measure organizational structure (Cronbach's alpha $=.71$ ); 14 statements measure organizational development (Cronbach's alpha $=.81$ ); 6 statements measure morale (Cronbach's alpha $=.78$ ). Statement responses - on a 5 point scale with 1 strongly agree, 5 strongly disagree, and 3 neutral - were coded so that a positive response indicated support for the concept (i.e., positive response indicated high morale). Conceptual quotients were created by calculating the mean response to the set of statements measuring the concepts. Accordingly, a quotient significantly below 3.0 (the assumed population mean on the 5-point scale) indicates positive agreement with the concept, and a quotient significantly above 3.0 indicates that respondents disagree with the concept (i.e., disagree with statements suggesting high morale).

\section{Comparisons between Management and Rank-and-File}

Organizational Development. The literature indicates that cultural change is difficult, requiring management and rank-and-file to adapt to new values, structures, routines, and goals. However, management and rank-and-file have different roles in the change process. Management is responsible for 
conceiving, guiding, and monitoring change, while rank-and-file must execute management's vision and live with the new roles and values associated with change. Management is expected to perceive OD initiatives more broadly, in concert with strategic organizational goals, and guide and assess the change process from a position of leadership and accountability. It is expected that management will perceive that its OD initiatives are rooted in sound strategies and practices, while rank-and-file will question the reasons for

The literature indicates that cultural change is difficult, requiring management and rank-and-file to adapt to new values, structures, routines, and goals. However, management and rank-andfile have different roles in the change process.

change and be sensitive to how it is implemented. This logic is the basis of the following hypothesis:

H1: Management will perceive it has done significantly better at OD than rank-and-file.

A $t$ test of independent samples was used to compare the OD quotients (mean value of the 14 statements in the construct) of management and rankand-file. This hypothesis is supported (management OD quotient $=2.87$, rankand-file OD quotient $=3.21$; mean difference $=.34 ; t$ value $=3.69 ; \mathrm{p}<.001$ ).

The data indicate that management believes OD initiatives have generally followed theoretical guidelines, as the OD quotient for management shows modest overall agreement with the statements (quotient is less than 3.0). Conversely, the rank-and-file OD quotient shows general disagreement that change initiatives are in accordance with the parameters defined by OD theory. Thus, there is not only a significant difference between the OD quotients, there is also a clear difference of attitudes: management perceives it has generally implemented change in accordance with OD, while rankand-file think the process of change has not adhered to ideas and practices consistent with successful OD. This finding is further reinforced by looking at the pattern of responses to the variable statements. Of the 14 OD statements, management agrees with 9 and rank-and-file agree with only 3 (see Table 1).

$T$ tests were also used to compare individual statement means, and there are significant differences on 11 of the 14 statements. Because the OD variable is a broad measure of change, with survey statements addressing planning, training, commitment, leadership, communication, participation, and a system of rewards, the significant differences on so many OD aspects reflect both the intensity and broad-based nature of the differences between the groups.

Six of the statistically significant OD statements show a clear difference of attitudes, with management agreeing with the statement and rank-and-file disagreeing. The two groups have differing opinions on some of the most 
TABLE 1

Organizational Development: Statement Comparison of Management and Rank-AND-File (14 statements, Cronbach's alpha = .B1)

ITEMS WERE ARRAYED ON A 5-POINT SCALE, RANGING FROM (1) STRONGLY AGREE TO (5) STRONGLY DISAGREE. T TESTS MEASURED WHETHER STATEMENT MEANS WERE SIGNIFICANTLY DIFFERENT BETWEEN THE TWO GROUPS.

$$
\begin{aligned}
& \text { Management } \\
& \text { Mean } \\
& N=66
\end{aligned}
$$

The newspaper's mission and core values are clearly understood by newsroom employees.

$I$ have been sufficiently trained to perform well in my job.

The top management team is unified in its commitment to change.

Management overestimated the level of resistance to change.

Management has been willing to scrap change initiatives that haven't worked.

The staff has participated in drafting change initiatives that affect their jobs.

The newsroom staff is open minded toward change.

I think management has adequately thought through the long-term implications of change initiatives.

Change initiatives and the reasons they are required have been communicated to the staff on a continuous basis.

Key top managers have taken on a strong leadership role in the change process.

Newsroom staff has been asked for feedback on changes that affect their jobs.

Change initiatives have helped develop a stronger trust between management and staff.

Management has been open and honest with staff about the reasons for change.

There is a system of rewards for

\begin{tabular}{|c|c|c|c|}
\hline $2.56^{* *}$ & 1.04 & 3.11 ** & 1.04 \\
\hline 2.22 & 1.03 & 2.42 & 1.09 \\
\hline $2.50^{*}$ & 1.23 & $2.82^{*}$ & 1.10 \\
\hline 3.21 & 1.24 & 3.03 & 1.04 \\
\hline $2.90^{\star}$ & 1.20 & $3.25^{\star}$ & 1.07 \\
\hline $2.85^{\star}$ & 1.19 & $3.20^{*}$ & 1.11 \\
\hline 3.32 & 1.09 & 3.14 & .98 \\
\hline $3.28^{*}$ & 1.17 & $3.64^{\star}$ & 1.05 \\
\hline $2.88^{*}$ & 1.14 & $3.18^{*}$ & 1.09 \\
\hline $2.26^{\star \star}$ & 1.06 & $2.75^{* *}$ & 1.09 \\
\hline $2.82^{* \star}$ & 1.18 & $3.35 * *$ & 1.14 \\
\hline $3.72^{\star}$ & 1.02 & $4.03^{*}$ & .88 \\
\hline $2.60 * *$ & 1.19 & $3.40^{* *}$ & 1.12 \\
\hline $3.27^{*}$ & 1.20 & $3.59^{*}$ & 1.09 \\
\hline
\end{tabular}
work that meets the goals of change initiatives.

Rank-and-file Mean S.D. $\mathrm{N}=444$

$3.11 *$ * 1.04

p $<.05$

$* * \mathrm{p}<.01$ 
basic aspects of change (means noted parenthetically). Management believes the newspaper's mission and core values are understood by newsroom employees (2.56), while rank-and-file are apparently unsure about their paper's mission and values (3.11). Management believes the staff has participated in drafting change (2.85), while rank-and-file disagree (3.20); and management says that it has asked for staff feedback about change (2.82), while rank-and-file apparently think management is not interested in feedback, or at least not interested enough to ask (3.35). The importance of communication in the change process is also shown, as management agrees that change initiatives and the reasons for change have been continually communicated (2.88), while rank-and-file disagree (3.18). Most telling about communication is the large difference of opinion concerning honesty. Management shows quite strong agreement that it has been open and honest with staff about the reasons for change (2.60), but rank-and-file exhibit equally strong disagreement (3.40). This .8 mean difference on honesty (on a 5-point scale) is the largest gap between the groups' responses to any of the 14 statements in the OD variable.

Even on the eight statements where the groups tend to agree, there are significant differences in their intensity of agreement on five statements. Although rank-and-file credit management for its strong leadership role (2.75) and unified commitment to change (2.82), management assesses its leadership role (2.26) and commitment (2.50) in significantly more optimistic terms. In those areas where management is relatively self-critical, rankand-file tend to be more critical. Management concedes it has not thought through the long-term implications of change (3.28), but rank-and-file take a harsher view (3.64); the scenario is similar concerning a system of rewards for work that meets the goals of change, with management disagreeing that such a system is in place (3.27), but rank-and-file disagreeing significantly more (3.59). This trend might be best shown with management's relatively strong disagreement to the statement that change initiatives have helped build stronger trust between management and rank-and-file (3.72). Management's response is a candid assessment of an unpleasant reality and a subtle admission of a failure of change; yet, rank-and-file are significantly harsher in their assessment (4.03), with their strongest level of disagreement to any of the 14 statements. These differences underscore that even when management and rank-and-file find areas of common ground, they still tend to disagree.

Of the 14 OD statements, management has a stronger level of disagreement to only 2 , and these 2 statements are among the 3 statements that do not have significant mean differences. Management disagrees that it has overestimated resistance to change (3.21), while rank-and-file are neutral (3.03); and managers disagree that the staff is open-minded toward change (3.32) marginally more than rank-and-file (3.14). Although not significant, taken together, the ideas that management perceives more resistance and less openmindedness suggest that management believes their staffs are generally resistant to change initiatives. This perception is likely to influence how managers approach leading change. Managers would be likely to view with 
more optimism the task of managing a staff that is open to new ideas and practices. Conversely, managers who perceive a resistant and inflexible staff are more likely to judge the task of leading change as more difficult.

Comparisons of Statements Not in the OD Variable. There were six statements appearing on both surveys that were not part of the OD variable. $T$ tests were performed on the responses, and significant differences were found on four of the statements. Two of the significant statements show a clear difference of attitudes. Management, consistent with other responses that show more optimism about change than rank-and-file, agrees that there has been a noticeable change in the newsroom culture that has improved the organization (2.76), while rankand-file disagree quite strongly

The increased profit pressure is ac:knowledged by the groups. with both agreeing strongly with the statement that there is more emphasis on prolits than there used to be. Considering the: extent of differences between the groups on most of the measures. it is quite: revealing that the groups believe with approximate expal strength that there is an increasing emphasis on profil. (3.58). This large difference of opinion (.82 on a 5 -point scale) underscores the different experiences and perceptions the two groups have about the impact of change on the newsroom culture. But the pattern of management optimism is reversed when the groups are asked about an indicator of journalism quality. In this case, rank-and-file agree that newspapers are doing a better job portraying a representative picture of society than in the past (2.61), while management is significantly more pessimistic, disagreeing with the statement (3.22). This finding could help explain why management sees a need to get closer to readers and redefine news to be more aligned with the lives of people in a changing and diverse marketplace.

Management and rank-and-file show similar attitudes toward two of the statements, and one of the responses is quite surprising. The two groups both slightly disagree that "Ilook forward to when change is no longer a large part of work." Given the difficulty of change, especially rank-and-file's general frustration with the process, it seems logical that rank-and-file have had enough change, but this is not the case. Rank-and-file actually disagree slightly more (3.15) to the statement than management (3.10). This finding supports an issue discussed earlier: management tends to perceive a culture of resistance to change; however, rank-and-file respond that they have accepted change as a part of work.

The increased profit pressure is acknowledged by the groups, with both agreeing strongly with the statement that there is more emphasis on profits than there used to be. Considering the extent of differences between the groups on most of the measures, it is quite revealing that the groups believe with approximate equal strength that there is an increasing emphasis on profit (management $=2.10$; rank-and-file $=1.89$ ). For both groups, their level of agreement was stronger with this statement than any of the 20 statements 
that appeared on both instruments.

Exploring the relationship between change and morale, both groups disagreed with the statement: "Morale in our newsroom appears to be getting better." However, consistent with statements that indicate management does not perceive the newsroom climate to be as bad as rank-and-file, there was a significant difference in the groups' level of disagreement. Management disagreed with the statement (3.28), but its disagreement was not nearly as strong as rank-and-file's (3.81).

\section{Rank-and-File Results}

Morale. Low morale among newspaper journalists has been an industry issue for more than a decade. OD research indicates that change initiatives tied to creating a different organizational culture can be threatening for employees because embodied in the new culture are new organizational values, work routines, job skills, and rewards. Based on this evidence, it was hypothesized:

H2: Morale among rank-and-file will be low (morale quotient significantly higher than 3.0 ).

The morale quotient is 3.32 . A one-sample $t$ test indicates the quotient mean is significantly higher than the assumed population mean $(t$ value $=$ 9.26; $\mathrm{p}<.001$ ). This hypothesis is supported.

Six statements comprise morale. $T$ tests on each statement and the assumed population mean found that 5 of the 6 statements were statistically significant. Respondents agreed with only one statement indicating high morale: "I am committed to this newspaper's plans for change" (2.57). Respondents were neutral to the notion that changes have given them more job skills (3.09), and they disagreed that changes have created more job autonomy (3.26). The remaining three statements constituting this concept make more general (non-first person) references to morale, and these had higher levels of disagreement (see Table 2).

Rank-and-file's relatively strong disagreement that changes have been implemented smoothly (3.58) supports theory that suggests change affecting jobs, skills, and values is difficult. This difficulty of embracing change draws more support from respondents' disagreement that there has been a positive change in the newsroom culture (3.58). However, most telling is the statement that is probably the purest measure of morale. Journalists show their highest level of disagreement to the idea that morale in our newsroom appears to be getting better (3.81).

News Values. The 14 statements that construct this study's measure of news values probe how rank-and-file journalists perceive newsroom changes have impacted their news judgment and news content. The news values quotient is 3.23. A one-sample $t$ test indicates the quotient mean is significantly higher than the assumed population mean $(t$ value $=8.41 ; \mathrm{p}<.001)$. Accordingly, rank-and-file have a negative attitude about changes in news values. In general, respondents think they are doing what they can to 


\section{TABLE 2}

\section{Morale (6 statements, Cronbach's alpha $=.78$ )}

ITEMS WERE ARRAYED ON A 5-POINT SCALE, RANGING FROM (1) STRONGLY AGREE TO (5) STRONGLY DISAGREE. T TESTS MEASURED WHETHER STATEMENT MEANS WERE SIGNIFICANTLY DIFFERENT THAN ASSUMED POPULATION MEAN (3.0).

$\begin{array}{llcc} & \text { Mean } & \text { Std. Dev. } & \text { N } \\ \begin{array}{l}\text { There has been a noticeable change in our } \\ \text { newsroom culture that has generally } \\ \text { improved our organization. }\end{array} & 3.58^{\star \star} & 1.10 & 454 \\ \begin{array}{l}\text { Morale in our newsroom appears to } \\ \text { be getting better. }\end{array} & 3.81^{\star *} & 1.00 & 456 \\ \begin{array}{l}\text { I am committed to this newspaper's } \\ \text { plans for change. }\end{array} & 2.57^{* *} & .95 & 454 \\ \begin{array}{l}\text { Change initiatives have given me } \\ \text { more job skills. }\end{array} & 3.09 & 1.13 & 453 \\ \begin{array}{l}\text { Change initiatives have created more } \\ \text { autonomy in my job. }\end{array} & 3.26^{\star *} & 1.07 & 454 \\ \begin{array}{l}\text { Generally, change initiatives have been } \\ \text { implemented smoothly. }\end{array} & 3.58^{* *} & .96 & 454 \\ \text { ** p <.01 } & & & \end{array}$

preserve some traditional journalism values in an era when newspapers are more market driven (see Appendix 2). Responses to the individual statements shed some light on specific news value issues that shape respondents' attitudes (statement means noted parenthetically). Journalists agree that newspapers are doing a better job portraying a representative picture of society than in the past (2.61), but they are neutral about whether papers are doing better at providing a truthful account of the day's events in a meaningful context than in the past (2.94). The rank-and-file journalists do not believe that content decisions are based solely on journalism criteria, as they agree strongly that more gossip, trivia, and non-news features are used to fill the paper (2.38) and recent changes in design stress style over substance to the point that look and feel of the paper are more important to editors than the depth of the news $(2,40)$. They have slight agreement that their newspaper has less breaking news than before change initiatives (2.88), and significant disagreement that changes in the industry have made papers more thoughtful and provocative (3.27). Journalists feel the impact of new methods and structures on their news values. They agree focus groups, surveys, and community meetings are good methods to generate ideas for news coverage (2.82), but they acknowledge an impact of organizational integration, showing strong agreement that journalists working at papers that have 
eliminated divisions between news and business are more likely to engage in self-censorship when writing about issues important to advertisers (2.36). And they disagree that change has increased resources for practicing journalism (3.57) and led to more investigative reporting (3.46). This point is underscored by journalists' agreement that an important issue is less likely to become news if it takes a great deal of time to uncover and report (2.66). The respondents see journalism independence, a traditional benchmark of news values and credibility, as on the road to obsolescence. Journalists agree that the opportunity for independent-minded publishers or editors to run their own newsrooms is coming to an end (2.30) and are neutral when asked whether the role models for today's managers are those editors and publishers who in the past told the truth when it was not popular or profitable to do so (2.93).

Organizational Structure. The quotient for the 12 statements that construct this variable is 3.55 , which a one-sample $t$ test shows is significant to the assumed population mean $(t$ value $=23.13, \mathrm{p}<.001$ ). This finding suggests that journalists generally responded negatively to the impact of changing newsroom structures. When viewed individually, the statement means indicate that journalists recognize that changes in structure (the most common being from beats to teams) have impacted their work, but seldom in ways theory would predict nor management would desire (see Appendix 3). Journalists indicate modest (but significant) agreement that they work more closely with their colleagues than in the past (2.89), but they agree much more strongly that newsroom changes have too often meant attending meetings that cut into time spent on journalism (2.05). Contrary to theory, rank-and-file don't see that restructuring the newsroom has flattened the hierarchy, disagreeing strongly that the number of layers of management has decreased (3.75). This finding is reinforced by nearly equally strong agreement that newsroom restructuring seems to require more editors who send out memos about the new goals of restructuring (2.42). The journalists in this sample are still wary of the impact of cross-departmental teams, indicating strong disagreement that directors of advertising, circulation, and marketing should participate in news planning (4.26). Also, they do not see a connection between the team structure and better journalism, disagreeing that reorganization has helped the staff better understand readers (3.53) and that work teams have improved product quality (3.11). Moreover, the rank-andfile see media executives as having different values than they do, with executives more focused on market and strategy than on the experiences of their employees (1.78); respondents also disagree strongly that structural changes place more emphasis on nonprofit goals (organizational efficiency, the latest technology, product quality, and worker autonomy and creativity) than profit goals (3.87).

Variables Affecting Morale. Considering the vast amount of change being implemented at newspapers in the sample and the difficulties associated with OD in general, a particular interest of this research project was to measure the impact of change initiatives on morale. Toward this end, the variables constructed to measure the three concepts common to change 
efforts at newspapers - OD, news values, and organizational structure were used as independent variables in a regression model to assess their relative impact on morale.

Because OD is a broad measure of change and OD initiatives impact an organization's structure and values, it was expected that the 4 variables (OD, news values, structure, and morale) would be highly correlated. This was indeed what occurred, as the correlations were all significant at the $\mathrm{p}<.001$ level. A colinearity test for tolerance showed these correlations did not violate the assumptions of multiple regression (SPSS, 1994). A multiple regression model was then built to test:

\section{H3: Rank-and-file perceptions of organizational development will predict morale.}

To control for the demographic variables of age, ethnicity, gender, experience, and duties, these variables were entered as a block into the regression model before the three independent variables. Experience, duties ("some managerial duties" or "no managerial duties"), and age were significant predictors in the block. Together, the demographic variables accounted for $5.77 \%$ of the variance (Adjusted R Square $=.0577$ ).

H3 is supported. Organizational development, entered as the second block in the model, explained $45.8 \%$ of the variance after controlling for demo-

\section{TABLE 3 \\ Regression Model - Beta Weights and $\mathbf{R}^{2}$ for Demographics, OD, Organizational Structure, and News Values on Morale}

$\begin{array}{lcccc}\text { Variable } & \text { Block 1 } & \text { Block 2 } & \text { Block 3 } & \text { Block 4 } \\ \text { Experience } & .327^{* *} & .183^{* *} & .089 & .113 \\ \text { Duties } & -.144^{* *} & -.176^{\star *} & -.151^{* *} & -.139^{* *} \\ \text { Age } & -.195^{*} & -.080 & -.036 & -.051 \\ \text { Ethnicity } & .040 & .051 & .033 & .028 \\ \text { Gender } & .036 & .056 & .033 & .003 \\ \text { Organizational } & & .679^{* *} & .484^{\star *} & .445^{\star *} \\ \text { Development } & & & & \\ \text { Organizational Structure } & & & .353^{* *} & .254^{* *} \\ \text { News Values } & & & & .191^{* *} \\ \text { Cumulative Adjusted } \mathrm{R}^{2} & .058 & .516 & .594 & .614 \\ \text { * } \mathrm{p}<.05 & & & & \\ \text { ** p<.01 } & & & & \end{array}$

graphics. OD is clearly the strongest predictor of morale among all the independent variables (see Table 3). Accordingly, the data indicate that as 
rank-and-file's attitudes toward OD become more positive their morale increases; or, as rank-and-file's attitudes toward OD become more negative their morale decreases.

After all the independent variables were entered in the regression model, OD, structure, and news values are significant predictors of morale. However, after controlling for demographics, the explained variance each variable adds differs notably. OD explains $45.8 \%$ of the variance, organizational structure accounts for $7.8 \%$ of the variance and news values accounts for $2.0 \%$. What is interesting is that news values, so basic to journalists' jobs and how they perceive their roles, explains a relatively small amount of the variance. Perhaps this is because in the midst of organizational changes that affect the most basic elements of work - schedules and routines - journalists continue to see the basic elements of news as information gathering, interviewing, writing, and editing. It is logical that news values impact morale, but change initiatives that require training and re-ordering of work priorities, as well as newsroom restructuring, are tangible symbols of a new culture. Because they are the most easily identified signs of change, they are the most likely targets for acceptance or resistance. Thus, it appears that changes most affecting morale are those $O D$ and restructuring initiatives that management believes will eventually reconstitute news. News values are changing, but the results suggest that among the types of change, rank-andfile see changing news values as having a smaller impact on their morale.

After all the variables were entered in the model, duties was also shown to be a significant predictor of morale. A dichotomous variable $0=$ no managerial duties, 1 = some managerial duties), the negative beta weight indicates an inverse relationship. In other words, journalists who have some managerial duties have significantly lower morale than those who have no managerial duties; or, those with no managerial duties have higher morale than those with some managerial duties. This result supports anecdotal evidence that change has been most difficult for low- and mid-level managers. These managers tend to get "squeezed" by change, expected to execute the change initiatives of top management while working most closely with non-managers.

Statements Not Part of Variables. The statements not part of variables also provide some useful insights (see Appendix 4). One of the research questions in this study was whether newsroom employees think the direction of change better fits the goals of journalism or marketing. As noted in the comparative results, of the 62 statements in the survey, rank-and-file's strongest agreement was with the statement: "There is more emphasis on maintaining or increasing the paper's profits than there used to be" (1.89). There was also strong agreement that newsroom managers have become increasingly aware of the concerns of stockholders and capital investors (2.13). Respondents think this increased awareness or pressure created by financial performance does not need to be expanded, as there is significant disagreement to the statement that the newspaper industry needs a culture that requires greater marketing intelligence in the newsroom (3.26). Taken together, these statements indicate rank-and-file journalists believe newspa- 
pers are becoming more sensitive to marketing and this movement has gone far enough.

There is also a concern about the ethical issues and threats to journalism independence that removing the wall between the news and business may initiate. There is strong agreement that ethical committees are needed to draft guidelines for editorial staff participation in promotional events (2.27) and significant agreement that journalistic independence has helped establish newspapers as credible (2.59). The journalists in this sample still use journalism excellence as the standard for quality, and they like competition. Even in the era of increased profit pressures, there is significant disagreement that most newspaper companies would trade Pulitzer Prizes for consistently high profits (3.36), and, in an apparent longing for days past, respondents show strong agreement that journalism has suffered in the era of one-newspaper towns (2.07).

There is additional evidence that rank-and-file do not perceive OD as progressing in accordance with theory. Rank-and-file disagree that management has done a good job preparing employees for change (3.38), and they disagree that management has done a good job measuring the results of

There is also a concern about the ethical issues and threats to journalism independence that removing the wall between the news and business may initiate. change (3.63). Respondents have even stronger beliefs that management is ego driven and inflexible. Rank-and-file agree that some managers have embraced formulas of change because they have invested so much money, time, and ego in them that they can't admit their lack of success (2.26). And there is a similar strong agreement to the idea that managers who have found resistance to change have responded by saying in effect, "The train is leaving the station, you can get on or get off" (2.27).

Furthermore, journalists don't see change meeting its stated objectives, as they show strong agreement there is little evidence that common changes (i.e., redefining of news, newsroom restructuring, and use of emerging technologies) are attracting more readers and advertisers (2.26).

The data also lend support to the idea that news managers and the growing number of consultants employed in newsrooms misunderstand journalists' resistance to change. The journalists in this study do not see themselves as opposed to change; in fact, they show significant disagreement to the statement that they look forward to when change is no longer such a large part of work (3.15). But journalists tend to like to be left alone to do their jobs which runs counter to theory that predicts workers are happier when they collaborate and more productive in teams. The more than 450 rank-and-file in this sample significantly agree with the statement: "I am happier when I can work alone" (2.64).

Analysis by Circulation. Because organizational resources are determined in part by an organization's size and group dynamics can be impacted by 
group size, this study explored whether newspaper size (measured by circulation) impacted respondents' attitudes toward change. To test for differences by circulation, means for each variable were calculated by circulation size ( 4 small papers with circulations less than 50,000; 7 mid-size papers with circulations between 50,000 and 250,000 [actual range is 71,000 to 156,000]; and 6 large papers with circulations more than 250,000).

\section{TABLE 4}

anova Tests of Variables by Circulation Size

RESPONSES ARE ON A 5-POINT SCALE, WITH 1 STRONGLY AGREE, 5 STRONGLY DISAGREE AND 3 NEUTRAL.

Circulation Size

\begin{tabular}{|c|c|c|c|c|c|c|}
\hline \multirow[b]{2}{*}{ Variable } & \multicolumn{2}{|c|}{ Small } & \multicolumn{2}{|c|}{ Mid-size } & \multicolumn{2}{|c|}{ Large } \\
\hline & $\begin{array}{l}\text { Mean } \\
\qquad \mathrm{N}=\end{array}$ & S.D. & $\begin{array}{c}\text { Mean } \\
\quad \mathrm{N}\end{array}$ & S.D. & $\begin{array}{r}\text { Mean } \\
\mathrm{N}\end{array}$ & $\begin{array}{l}\text { S.D. } \\
92\end{array}$ \\
\hline Morale & $3.53^{* *}$ & .64 & 3.33 & .75 & 3.23 & .70 \\
\hline News values & 3.29 & .56 & 3.20 & .58 & 3.23 & .55 \\
\hline Org. Dev. & $3.36^{*}$ & .54 & 3.19 & .61 & 3.17 & .53 \\
\hline Org. Structure & 3.58 & .48 & 3.53 & .50 & 3.56 & .50 \\
\hline
\end{tabular}

The data show that small newspapers are having more difficulty with change as it relates to two variables: $O D$ and morale (see Table 4). A one-way analysis-of-variance test indicates that morale is significantly lower at small papers; also, small paper respondents indicate significantly higher disagreement that OD initiatives have been in accordance with theory. It is worth noting that the means for all four variables are higher for small papers.

These results also reveal no significant differences between mid-size and large papers. But perhaps more telling about this analysis is that there is not a positive attitude toward any of the variables at any size paper. In other words, even though some aspects of change are more difficult at small papers, these strata show that respondents do not believe change has gone well (or in accordance with theory) on any of the measures, regardless of newspaper size.

\section{Discussion}

The challenge of change from the standpoint of management is getting 
rank-and-file to accept the core values that embody management's vision for a transformed newsroom culture. The data provide strong evidence that management's $O D$ initiatives are failing to win rank-and-file support regardless of whether the initiatives are in concert with theory. What is surprising in these findings is the extent to which management and rankand-file disagree and how often.

Of the 20 statements that appeared on both surveys, there are significant differences on 15 of them. Of these 15, the responses to 9 statements indicate clear differences of attitudes, with one group agreeing and the other disagreeing. Of the 14 statements that construct the OD variable, there are significant differences on responses to 11 statements. Taken as a whole, the responses show that many important divi-

The challenge of change from the standpoint of management is getting rankand-file to accept the core: values that embody management's vision for a transformed newsroom culture. sions exist between management and rank-and-file, and even when the groups can agree, they often disagree on their level of agreement. In many instances the gap between responses is so large that it is hard to understand the two groups are sharing the same experiences, and perhaps they are not. The groups' roles in the change process differ. The sample of newsroom managers in this study is comprised of many of the nation's leading editors. Their involvement in the ASNE Change Committee reflects their interests beyond the walls of their newsrooms, and suggests they positioned themselves as leaders in an industry-wide effort to respond to the forces mandating change. The rank-and-file in this sample must adapt to management's vision by executing their jobs in accordance with the new procedures and goals of change. Despite these different roles, however, as part of the same organizations, management and rank-and-file should share similar values. Both groups are journalists.

Management's self-assessment may be a bit optimistic, but it is grounded in reality and is at times unflatteringly candid. Managers have a great deal invested in change initiatives, both in terms of organizational resources and their individual careers. A role of management is to "see the big picture," which suggests that management should be able to assess the process and progress of change within its overall strategic goals better than rank-and-file. Thus, management's general optimism regarding change may be a reflection that the broader process is proceeding in the right direction, even if certain aspects tend to get off course. The data support this. Management gives itself high marks for leadership and generally following the prescriptions for change articulated in OD models and theory. Management views itself as trying to do what should be done to enable change to succeed. Yet, as Kanter (1983) suggests, change requires a "leap of faith" to get people to embrace an organizational reality that is not yet known. And on this issue, the data show management to be quite honest, admitting the entire change formula has not been worked out. Even more candid, however, is management's admission 
that certain parts of the process that it can control have not been wellmanaged. Management concedes that it has not adequately thought through the long-term implications of change, and it acknowledges there is not a system of rewards for work that meets the goals of change initiatives. Accordingly, it is not surprising that management recognizes that its shortcomings have contributed to a breakdown of trust with rank-and-file, while at the same time perceiving a cultural change that has improved the organization. This apparent contradiction must be perplexing and difficult for newsroom managers. There is some evidence in the data that managers are a bit frustrated, placing the "blame" for a lack of success on rank-and-file, who are perceived as close minded and resistant to change.

However, the results from the rank-and-file survey suggest it is not accurate to simply dismiss journalists as resistant to change. Rank-and-file indicate they accept change as a part of work and are personally committed to their paper's change efforts. They credit their managers for taking leadership roles and being committed to change. However, they question the factors motivating change and are able to distinguish between intentions and results. In brief, while management says it has articulated a vision, included employees in creating changes, been flexible, and sought feedback about Rank-and-file's perception that management has failed at nearly every step of the process, combined with their sense: that profit is increasingly imporlant lo newsrom managers, further explains the low level of lrust rankamd-file express loward their managters. the change process, rank-and-file respond that they are confused about the vision, feel left out of the process, and perceive their managers as inflexible. Rank-and-file also sense management's vulnerability and frustration in leading change, showing strong agreement that change is ego driven by inflexible managers who, refusing to recognize its lack of success, resort to authoritarian measures to counter pockets of resistance. Rank-and-file's perception that management has failed at nearly every step of the process, combined with their sense that profit is increasingly important to newsroom managers, further explains the low level of trust rank-and-file express toward their managers. Numerous scholars cite trust as a prerequisite condition for successful OD initiatives. Thus, despite management's general optimism about an improving newsroom culture, the breakdown of trust that both management and rank-andfile acknowledge does not bode well for continuing efforts at change, as theory suggests and common sense reveals that people do not readily accept the ideas of those whom they do not trust.

Beyond the organizational development issues associated with change, rank-and-file's skepticism about change can be understood by an apparent lack of producing successful results. Change initiatives are not only failing to create more efficient, productive, and happier newsrooms, they are also falling short on their stated goals. Journalists don't perceive changes as 
attracting more readers and advertisers, or helping to produce better newspapers. Instead, rank-and-file connect change initiatives with fewer resources for journalism in a more market-driven culture and industry.

Kanter (1983), Drucker (1995), Bergquist (1993), and many organizational scholars would suggest that "breaking down the wall" between the newsroom and other departments in the news organization is an important step toward creating the "integrated" and "innovative" organizational culture required to meet challenges swiftly and capitalize on opportunities in the postmodern business world. The data in this study suggest that rank-and-file perceive the new, integrated culture as a threat to their values, most of which are rooted in journalism. Much of rank-and-file's resistance to change is related to a sense that the "journalism-based" culture of their newsrooms is being replaced with a culture that places less value on journalism norms. In this way, there is a cultural "battle" unfolding in news organizations as they become more integrated. Harris (1998), writing about the clash that occurs when an organization attempts to create a market-oriented culture, asserts that the market-oriented values that define the culture must come to dominate the existing cultures for the transformation to succeed. This study indicates that this type of cultural struggle is being waged in newsrooms experimenting with change. When viewed in this regard, resistance to change can be understood as both rational and part of a cultural conflict. However, if cultural change is achieved through a combination of macro (values and beliefs) and micro forces (the tangible things such as practices, policies, and procedures that define daily life in the organization), then management's attempt to change the newsroom culture by changing the organization's structure and work routines appears to be well-advised and well under way.

This study also opens for re-examination several theoretical assumptions. The idea that modern newspaper organizations are characterized by complex, hierarchical bureaucracies and specialized labor appears to be less accurate today than it was before "change" became an industry buzzword and organizational goal. Media corporations, no doubt large bureaucracies, can however be understood to be "disassembling the assembly line." The goals of $O D$ and change most often focus on creating flatter corporate flowcharts with the expectation that employees need to be more versatile and multiskilled. Clearly, this is the opposite of labor specialization. Furthermore, the empowerment assumptions of restructuring hierarchical organizations into flatter, team-based units have not materialized for the rank-and-file journalists in this sample. Rank-and-file understand restructuring as a mechanism that affords them fewer resources to practice journalism, and, contrary to theory, rank-and-file perceive restructuring has created more layers of managers and a more "managed" newsroom. The journalists in this sample say that the team-based structure has not brought them more autonomy, nor has it provided more decision-making authority.

It is possible that the empowerment expected to result from restructured newsrooms is misconceived. A primary rationale for less hierarchical organizations is the team-based structure unleashes the knowledge and creativity 
of lower level employees (Drucker, 1990; Kanter, 1983; Hirschhorn, 1991). This view presupposes that management, under the hierarchical structure, has not previously afforded employees the power to effectively utilize these assets. However, this assumption seems to neglect the nature of newspaper work, which has traditionally afforded rank-and-file a great deal of latitude, encouraging journalists to apply their knowledge and be creative. Long before empowerment became a management cliché, Gassaway's 1984 social construction work found that rank-and-file journalists and newspaper managers negotiate for power, with rank-and-file having considerable leverage, because as newsgatherers they control the initial flow of information. Furthermore, journalism is one of the few occupations where employees at the bottom of the corporate ladder consider themselves professionals. Valuable newsroom employees have long been those who could work well on their own, digging for stories and building relationships with sources. Interviewing is a craft, writing and design are forms of self-expression, and editing is a skill built on an individual's grasp of language and professional values. To require journalists to give up the individual nature of their work asks them to sacrifice some of the skills that have become a part of their professional identities. There is strong evidence in this study that journalists have not accepted the idea that team-based newsrooms empower them or better utilize their skills. This finding supports previous research (Neuzil, et al., 1999) and reinforces the idea that the organizational theory that managers are using to empower their employees and restructure their newsrooms could be misapplied, as it misunderstands the nature of newspaper journalism work.

The assumptions about the organizational role of management are changing, too. This study finds little support that newsroom managers are "technocrats" who value organizational and technical development more than the profit goals of their "capitalist" owners. The data indicate it is more accurate, as Kanter (1983) and others suggest, to understand change as a process of integration, where the marketing goals of the traditional "business side" of the news organization have become more apparent to journalists and more valued by management throughout the organization (my italics). Galbraith's "approved contradiction" concept (1978) - that innovative managers will focus on professional and organizational goals while returning just enough profit to keep their capitalist owners satisfied - is a core assumption of Demers' research on the corporate newspaper $(1996,1999)$. This study found little support for the existence of an approved contradiction; rather, managers and rank-and-file perceive change as both market and profit driven at the expense of organizational issues thought to be of prime concern to professional managers (product quality, technology, and employee development). These findings suggest that modern news executives are no longer "techno- 
crats" in the sense Galbraith defined them, but are closer to the "capitalists" who sought maximum financial return on their investments. The practice of offering newsroom managers incentives (salary bonuses or stock options) tied to the financial performance of the company is one way corporations subtly "disapprove" of the approved contradiction.

Limitations of the study. An obvious shortcoming of this survey method is that it can only provide a "snapshot" of attitudes at the time of the study. Change is an ongoing process, and the instruments used can only provide a one-time glimpse of the process. As the change process unfolds in newsrooms across the country, it would be wise to continue to monitor change initiatives and journalists' attitudes toward them. Also, this study did not attempt to measure the amount of change or the phases of the change process. Thus, while all the respondents have a commonality of change experiences, it is not clear if attitudes toward change differ based on the amount of change or stages in the change process.

There is also a chance to refine the instruments and measures of change used in this study. Organizational development research has generally focused on one organization at a time, using site-specific variables. By taking a different approach, there were very few established measures. Accordingly, the attempt here was to create "tools" from which scholars can begin to empirically assess change.

Suggestions for future research. The findings in this study point to several theoretical areas that should prove fertile ground for exploration. This study adds to the small amount of research that suggests restructuring newsrooms into team-based systems does not "empower" journalists in the manner theory predicts. If team-based newsrooms are the future of the industry, then changing organizational relationships spawned by restructuring offer interesting opportunities for study. Among some of the questions these changes suggest: Do team-based structures impact the ways journalists work with one another? Do teams impact the ways journalists develop relationships and interact with their sources? Do teams require and reward different personality traits? How does the resourceful journalist, the "gumshoe" who worked well alone, often producing front page stories in the beat system, perform in the team structure? Do team-based newsrooms produce different content than the beat system does? And possibly most important to understanding the values that will drive the industry in the future are the questions of management influence and power. Do newsroom managers and editors see themselves as the innovative "technocrats" that theory presupposes? How much influence do newsroom managers have when it comes to setting the vision for change? To what extent do newsroom managers embrace the changes they are expected to lead? These questions, along with the need to develop better change-related measures over time (throughout the process of change), provide an abundance of directions for research.

\section{Conclusion}

This study surveyed a purposive sample of the nation's newspaper managers most experienced in industry-wide change initiatives; it also surveyed 
a much larger sample of rank-and-file from those same papers. The managers in this study have, in effect, used their newsrooms as laboratories to experiment with new and far-reaching change initiatives. These changes have become - depending on whom you ask - new standards of excellence or points of controversy and resistance. Although the results from this purposive sample cannot be generalized to the entire industry, the relatively large sample gives a good indication of what change has meant to journalists at newspapers on the cutting edge of industry-wide change. These findings should prove useful for the many news managers and editors who find their newsrooms embarking on or considering similar change initiatives. This study has also tested the key concepts of organizational development, making it one of only a few attempts to understand the complexities of newspaper industry change through the lens of organizational theory. Given the size of the sample and the scope of the newspapers (circulations ranging from 5,000 to more than $1,000,000$, including public, private, and family-owned papers that are located in every major geographic region of the country), this study represents one of the largest scale attempts to date to assess journalists' perceptions about change initiatives that are sweeping through newsrooms nationwide.

Management, despite some reservations about the market-driven nature of change, thinks it is doing reasonably well following the guidelines of organizational development in a manner consistent with creating a more outer-directed and reader-driven newsroom culture. In short, management believes it has "managed" the change process in general accordance with theory. Rank-and-file, on the other hand, feel more victims of change than participants in it. The gulf between management and rank-and-file experiences with change has facilitated a breakdown in trust that could seriously hamper ongoing change initiatives. Morale among rank-and-file is low, and data suggest it is getting worse.

The newspaper industry finds itself in the throes of a cultural revolution precipitated by internal and external forces. Yet, the industry remains highly profitable and has shown resiliency in the information age, remaining a respected and widely utilized source of news and information. The predictions of doom are far from materializing, but many of the challenges that served as catalysts for cultural change remain. The findings of this study suggest there is a struggle unfolding between the core values of two cultures - marketing and journalism - and rank-and-file perceive organizational 
development efforts are focused on creating a more dominant marketing culture, often at the expense of journalistic norms.

This study has extended previous change research by approaching the problem differently. Organizational research has seldom been conducted on more than one organization at a time, and its methods are usually qualitative. The constructs in this study held up quite well to tests of reliability and statistical analysis, showing the depth of common experiences of journalists at newspapers implementing change. An important methodological finding of this study is that change can be studied at more than one newspaper at a time. Studies that go beyond site-specific variables are possible, which should encourage more research using larger, representative samples with the goal of testing and building theory. 
Appendix 1: Return Rates by Newspaper

\begin{tabular}{|c|c|c|c|c|c|c|c|}
\hline \multirow{2}{*}{ Paper } & \multirow{2}{*}{\multicolumn{2}{|c|}{ Managers }} & \multicolumn{2}{|c|}{ Rank-and-File } & \multicolumn{2}{|c|}{ Total } & \multirow{2}{*}{$\begin{array}{r}\text { Percent } \\
\text { Returned }\end{array}$} \\
\hline & & & Sent & Returned & Sent & Returned & \\
\hline $\begin{array}{l}\text { Missourian } \\
\text { Columbia, Mo. }\end{array}$ & 2 & 2 & NA & NA & 2 & 2 & 100 \\
\hline $\begin{array}{l}\text { The Daily Chronicle } \\
\text { Dekalb, Ill. }\end{array}$ & 6 & 4 & 10 & 4 & 16 & 8 & 50 \\
\hline Missoulian (Mont.) & 6 & 1 & 31 & 23 & 37 & 24 & 64.9 \\
\hline Grand Forks (N.D.) Hera & Id 8 & 2 & 48 & 23 & 56 & 25 & 44.6 \\
\hline $\begin{array}{l}\text { The Free Lance-Star } \\
\text { Fredericksburg, Va. }\end{array}$ & 10 & 2 & 48 & 22 & 58 & 24 & 41.4 \\
\hline $\begin{array}{l}\text { The Bakersfield } \\
\text { Califomian }\end{array}$ & 13 & 4 & 25 & 17 & 38 & 21 & 55.3 \\
\hline Wichita (Kan.) Eagle & 10 & 4 & 37 & 23 & 47 & 27 & 55.3 \\
\hline Honolulu Advertiser & 10 & 6 & 30 & 20 & 40 & 26 & 65 \\
\hline $\begin{array}{l}\text { The Gazette } \\
\text { Colorado Spgs, Colo. }\end{array}$ & 15 & 7 & 39 & 28 & 54 & 35 & 64.8 \\
\hline $\begin{array}{l}\text { The State } \\
\text { Columbia, S.C. }\end{array}$ & 12 & 4 & 46 & 29 & 58 & 33 & 56.9 \\
\hline $\begin{array}{l}\text { The News Tribune } \\
\text { Tacoma, Wash. }\end{array}$ & 14 & 8 & 34 & 21 & 48 & 29 & 60.4 \\
\hline Dayton Daily News & 11 & 4 & 49 & 28 & 60 & 32 & 53.3 \\
\hline San Jose Mercury News & 9 & 1 & 64 & 31 & 73 & 32 & 43.8 \\
\hline St. Louis Post-Dispatch & 11 & 3 & 56 & 28 & 67 & 31 & 46.3 \\
\hline Kansas City Star & 12 & 2 & 68 & 35 & 80 & 37 & 46.3 \\
\hline The Oregonian & 7 & 7 & 58 & 40 & 65 & 47 & 72.3 \\
\hline $\begin{array}{l}\text { Star Tribune } \\
\text { Minneapolis, Minn. }\end{array}$ & 10 & 1 & 66 & 37 & 76 & 38 & 50 \\
\hline The Los Angeles Times & 16 & 6 & 98 & 48 & 115 & 54 & 46.1 \\
\hline Totals & 182 & $\begin{array}{c}68 \\
(37.3 \%)\end{array}$ & 807 & $\begin{array}{c}457 \\
(56.6 \%)\end{array}$ & 989 & 525 & 53.1 \\
\hline
\end{tabular}




\section{Appendix 2: News Values (14 statements, Cronbach's alpha $=.75)$}

Items were arrayed on a 5-point scale, ranging from (1) strongly agree to (5) strongly disagree. $T$ tests measured whether statement means were significantly different than assumed population mean (3.0).

Changes in the newspaper industry have generally made newspapers
more thoughtful and provocative.
The role models for today's newspaper managers are those editors
and publishers who in the past told the truth when it was not
popular nor profitable to do so.

Mean

Std. Dev.

Newspapers are doing a better job portraying a representative picture $2.61^{* *}$

of society than in the past.

Most of the changes undertaken by this newspaper have resulted in more resources -- human, technical, and/or financial support -for practicing journalism.

Focus groups, surveys, and community meetings are good methods

to generate ideas for news coverage.

This newspaper does more investigative reporting than it used to.

Journalists at dailies that have eliminated the divisions between the news and business departments are more likely to engage in selfcensorship when writing about issues important to advertisers.

Newspapers are doing a better job providing readers a truthful account

An important issue is less likely to become news if it takes

$-p<.05$

$* * p<.01$ 


\section{Appendix 3: Organizational Structure (12 statements, Cronbach's alpha $=.71)$}

Items were arrayed on a 5-point scale, ranging from (1) strongly agree to (5) strongly disagree. $T$ tests measured whether statement means were significantly different than assumed population mean (3.0).

I work more closely with my colleagues than I did in the past.

Management places more emphasis on nonprofit goals

(i.e., product quality, organizational efficiency, the latest technology, worker autonomy, and creativity) than profit goals.

Directors of advertising, circulation, and marketing should participate in news planning and budget meetings.

Work teams have improved product quality.

The number of layers of management in the newsroom has decreased in the past few years.

Restructuring in the newsroom seems to require more editors who send out memos about the new goals of the restructuring.

Top executives of media corporations live in worlds closely linked to market trends and business strategies but very far from the deeper currents of experience of their employees.

Changes in the newsroom have too often meant attending meetings that cut into the time we concentrate on journalism.

Change initiatives have helped below-average performers under the old system become more valuable to the staff.

Journalists in teams have more decision-making power than those who work on their own.

Reporters and editors who were newsroom stars before teams were created have adapted well to the team structure.

Reorganization has helped our staff better understand our readers.
Mean

2.89*

$3.87 * *$

Std. Dev.

1.04

$4.26^{* *}$

$3.11^{*}$

1.05

$3.75^{* *}$

1.24

$2.42^{* *}$

1.04

$1.78^{* *}$

.89

$2.05^{* *}$

1.02

$3.43^{* *}$

- $\mathrm{p}<.05$

$* * p<.01$ 


\section{Appendix 4: Statements Not Part of Variables}

Items were arrayed on a 5-point scale, ranging from (1) strongly agree to (5) strongly disagree. $T$ tests measured whether statement means were significantly different than assumed population mean (3.0).

Journalistic independence has helped establish the newspaper industry as a credible and distinct institution.

Newspapers should set up ethics committees to draft guidelines that put limits on editorial staff participation in promotional events.

I look forward to when change is no longer a large part of work.

There is more emphasis on maintaining or increasing the paper's profits than there used to be.

Most newspaper companies would trade Pulitzer Prizes

for consistently high profits.

Newsroom managers have become increasingly aware of the concems of stockholders and capital investors.

Management has done a good job preparing newsroom employees for changes that have taken place.

The newspaper industry needs a culture that requires greater marketing intelligence in the newsroom.

Journalism has suffered in the era of one-newspaper towns.

There is little evidence that changes in news operations (i.e., redefining of news, newsroom restructuring, and use of emerging technologies) are attracting more readers and advertisers.

The press should continually ask itself what it can do to improve the American democratic process.

Some newsroom managers have embraced formulas of change because they have invested so much time, money, and ego in them that it has become difficult to recognize or admit the lack of their success.

Managers advocating a new direction for news and having found resistance from their staff have responded by saying in effect ...

"The train is leaving the station, you can get on or get off."

Increasingly, top managers and editors seem to be retained or fired on the basis of profits more than journalistic performance.

I am happier when I can work alone.

Management has done a good job measuring the results of change.

$* \mathrm{p}<.05$

** $p<.01$
Mean

$2.59 * *$

2.27 **

Std. Dev. $N$

$1.89^{* *}$ 


\section{References}

Albers, R. (1995, April). New age newsrooms: Is reorganization the cutting edge or a passing fad? Presstime, 32-35.

Altschull, J. H. (1995) Agents of power: The media and public policy. White Plains, NY: Longman.

Argyris, C. (1974). Behind the front page: Organizational self-renewal in a metropolitan newspaper. San Francisco: Jossey-Bass.

Argyris C. (1993). Knowledge for action: A guide to overcoming barriers to organizational change. San Francisco: Jossey-Bass.

Beam, R. (1998). What it means to be a market-oriented newspaper. Newspaper Research Journal, 19 (3), 2-20.

Beam, R. (2000). Influences on a daily newspapers' market orientation. Paper presented at the conference for the Association of Educators of Journalism and Mass Communication, Phoenix, AZ.

Beam, R. (2001). Content differences between daily newspapers with strong and weak market orientations. Paper presented at the conference for the Association of Educators of Journalism and Mass Communication, Washington, DC.

Bedal, S. (1995, November/December). Building a better newspaper. The Editor, 13-15.

Bergquist, W. (1993). The postmodern organization: Mastering the art of irreversible change. San Francisco: Jossey-Bass.

Breed, W. (1955, May). Social control in the newsroom: A functional analysis. Social Forces, 326-335.

Broder, D. (1990, January 3). Democracy and the press. Washington Post, A15.

Brown, R. J. (1991). Cooperatives in managerial transition: What is the least disruptive way to introduce change? Management Quarterly, 32 (1), 22-24.

Cameron, K., \& Whetten, D. (Eds.). (1983). Organizational effectiveness: A comparison of multiple models. New York: Academic Press.

Cameron, K., Freeman, S., \& Mishra, A. (1993). Downsizing and redesigning organizations. In G. P. Huber \& W. Glick (Eds.). Organizational change and redesign: Ideas for improving performance, 19-63. New York: Oxford University Press.

Campbell, C. (1998, January 21). Newspaper change presentation and handout. School of Journalism, University of Missouri.

Connor, D. R. (1992). Managing at the speed of change: How companies experience it and leaders guide it. New York: The Free Press.

Coyle, J. (1998, July/August). Now, the editor as marketer. Columbia Journalism Review, 37 41.

Cunningham. B. (2001, September/October). The art of managing morale. Columbia Journalism Review, 34-36.

Deans, S. (1998, March 11). Newspaper change presentation and handout. School of Journalism, University of Missouri.

Demers, D. (1996). The menace of the corporate newspaper: Fact or fiction? Ames, Iowa: Iowa State University Press.

Demers, D. (1999). Corporate news structure, social control and social change. In D. Demers \& K. Viswanath (Eds.). Mass media, social control, and social change: A macrosocial perspective, 375-397. Ames, Iowa: Iowa State University Press.

De Jager, P. (2001, May/June). Resistance to change: A new view of an old problem. Futurist, 35 (3), 24-27. 
Dillman, D. (1978). Mail and telephone surveys: The total design method. New York: John Wiley.

Drucker, P. (1990). The emerging theory of manufacturing. Harvard Business Review, 68 (3), 94-102.

Drucker, P. (1995). Managing in a time of great change. New York: Truman Talley Books/ Dutton.

Editor \& Publisher International Yearbook. (1997). New York: Editor \& Publisher.

Eisenberg, E., \& Riley, P. (1988). Organizational symbols and sense making. In G. Goldhaber \& G. Barnett (Eds.). Handbook of organizational communication, 131-150. Norwood, NJ: Ablex.

Evans, P., \& Wurster, T. (1997, September-October). Strategy and the new economics of information, Harvard Business Review, 71-82.

Fairhurst, G. (1993). Echoes of the vision: When the rest of the organization talks total quality. Management Communication Quarterly, 6, 331-371.

Fallows, J. (1996). Breaking the news: How the media undermine American democracy. New York: Pantheon.

Fisher Jr., J. (2000, Winter). Envisioning a culture of contribution. Journal of Organizational Excellence, 47-54.

Gade, P., \& Perry, E. (2000). Leadership, values and cultural change: A three-year case study of the St. Louis Post-Dispatch. Paper presented at the conference for the Association of Educators of Journalism and Mass Communication, Phoenix, AZ.

Gade, P., \& Perry, E. (2003). Changing the newsroom culture: A four-year case study of organizational development at the St. Louis Post-Dispatch. Journalism and Mass Communication Quarterly, 80 (2), 327-347.

Galbraith, J. K. (1978). The new industrial state. Boston: Houghton Mifflin.

Gassaway, R. (1984). The social construction of journalistic reality. Unpublished doctoral dissertation, University of Missouri.

Gentry, J. (1993). Analysis of change at a small daily newspaper. Unpublished doctoral dissertation, University of Missouri.

Gentry, J. (1996). A roadmap for change. Unpublished model for change developed with support from the American Press Institute.

Gentry, J. (1997). Keys to success: Change survey results. ASNE Change: Annual Report of the ASNE Change Committee, 21.

Giles, R. (1991). Newsroom management: A guide to theory and practice. Detroit: Media Management Books, Inc.

Giles, R. (1993, Spring). Change shapes trends in newspaper management. Newspaper Research Journal, 14 (2), 32-39.

Harris, L. (1998). Cultural domination: The key to a market oriented culture? European Journal of Marketing, 32 (3/4), 354-373.

Harris, L., \& Ogbonna, E. (2000). The responses of front-line employees to market-oriented culture change. European Journal of Marketing, 34 (3/4), 318-340.

Haswell, C. (1995, December). Editors wrestle with change. The American Editor, 10-11.

Hickey, N. (1998, July/August). Money lust: How pressure for profit is perverting journalism. Columbia Journalism Review, 28-36.

Hickey, N. (2001, September/October). Low - and getting lower. Columbia Journalism Review, 37-39.

Hirsch, R., \& Thompson, T. (1994). The stock market as audience: The impact of public ownership on newspapers. Excerpted from: Audience making: How the media create the audience. Thousand Oaks, CA: Sage Publications. 
Hirschhorn, L. (1991). Managing in the new team environment. New York: Addison-Wesley.

Jeffers, D., \& Lewis, N. (1989). A case study of newspaper employee perceptions of communication variables related to organizational culture, immediate supervisor, and top management. Paper presented at the conference for the Association of Educators of Journalism and Mass Communication, Washington, DC.

Kanter, R. M. (1983). The change masters: Innovation for productivity in the American corporation. New York: Simon and Schuster.

Kets de Vries, M. (1993). Leaders, fools, and imposters: Essays on the psychology of leadership. San Francisco: Jossey-Bass.

Kurtz, H. (1993). Media circus: The trouble with America's newspapers. New York: Times Books.

Labianca, G., Gray, B., \& Brass, D. (2000). A grounded model of organizational schema change during empowerment. Organizational Science, 11 (2), 235-257.

Lambeth, E., Meyer, P., \& Thorson, E. (1998). Assessing public journalism. Columbia, MO: University of Missouri Press.

Lewin, K. (1947). Frontiers in group dynamics: Concept, method and reality in social science; social equilibria and social change. Human Relations, 1 (June), 5-41.

Lewis, L. (1999). Disseminating information and soliciting input during planned organizational change. Management Communication Quarterly, 13 (1), 43-75.

Lewis, L., \& Seibold, D. (1998). Reconceptualizing organizational change implementation as a communication problem. In M. Roloff. (Ed.). Communication Yearbook 21 (93-151). Newbury Park, CA: Sage.

Martin, H. (1998). Measuring newspaper profits: Developing a standard of comparison. Journalism \& Mass Communication Quarterly, 75 (3), 500-517. 5.

McGuire, T. (1994, October). Sharing the excitement of newspaper change. ASNE Bulletin,

Merrill, J. C. (1974). The imperative of freedom: A philosophy of journalistic autonomy. New York: Hastings House.

Merritt, D. (1996, July/August). Missing the point. American Journalism Review, 29-31.

Miller, V., Johnson, J., \& Grau, J. (1994). Antecedents to willingness to participate in planned organizational change. Journal of Applied Communication Research, 22, 59-80.

Mitchell, G. (1999, December 4). Two-way street. Editor \& Publisher, 20-21.

Morton, J. (1998, March). Newsprint prices: Rising again? American Journalism Review, 56.

Morton, J. (1999, June). Everything is coming up profits for papers. American Journalism Review, 80.

Morton, J. (2000, April). Who will be next? American Journalism Review, 72.

Narver, J. C., \& Slater, S. F. (1990, October). The effect of a market orientation on business profitability. Journal of Marketing, 54, 20-35.

Neuzil, M., Hansen, K., \& Ward, J. (1999). Twin Cities journalists' assessment of topic teams. Newspaper Research Journal, 20 (1), 2-16.

Nicholson, J. (2000, March 13). Newspaper ads top $\$ 46$ billion, eighth consecutive annual record. Editor \& Publisher, 49.

O'Brien, C. (2001, March 19). Resignation touches a nerve in the newspaper industry. San José Mercury News. Accessed March 23, 2001, online at http://www.mercurycenter.com/local/ center/newspaper0320.htm

Oring, C., \& Danko, P. (1995, June). Kissing the newsroom goodbye. American Journalism Review, 31-35, 43. 
Peck, C. (1996). Finding our way means revising our values. ASNE journalism values handbook. American Society of Newspaper Editors.

Peck, L. (1991, December). Anger in the newsroom. Washington Journalism Review, 22-27.

Picard, R., \& Brody, J. (1997). The newspaper publishing industry. Boston: Allyn and Bacon.

Piercy, N. F. (1997). Market-led strategic change: Transforming the process of going to market. Butterworth-Heinemann: Oxford, England.

Pincus, J., Knipp, J., \& Rayfield, R. (1988). Internal communication and job satisfaction revisited. Paper presented at the conference for the Association of Educators of Journalism and Mass Communication, Portland, OR.

Potter, W. (1998, April). Who owns what: Regional-cluster maneuvers help drive market. Presstime, 29.

Randolph, W. A. (2000). Re-thinking empowerment: Why is it so hard to achieve? Organizational Dynamics, 29 (2), 94-107.

Rappleye, C. (1998, January/February). Cracking the church-state wall. Columbia Journalism Review, 20-23.

Ridder, T., Rossi, S., Connors, M. J., \& Ceppos, J. (2001, September/October) Speaking for Knight Ridder. Columbia Journalism Review, 1.

Rogers, E. (1995). Diffusion of innovations (4th ed.). New York: Free Press.

Rosen, J. (1997). Losing the thing you love. ASNE Change: Annual Report of the ASNE Change Committee, 8-13.

Rosen, J., \& Merritt, D. (1994). Public journalism: Theory and practice. Dayton, OH: Kettering Foundation.

Rosenstiel, T. (1993). Strange bedfellows: How television and the presidential candidates changed American politics, 1992. New York: Hyperion.

Russial, J. T. (1997). Topic-team performance: A content study. Newspaper Research Journal, $18(1 / 2), 126-144$.

Schneider, B., Brief, A., \& Guzzo, R. (1996, Spring). Creating a climate and culture for sustainable organizational change. Organizational Dynamics, 7-19.

Schudson, M. (1995). The power of news. Cambridge, MA: Harvard University Press.

Senge, P. (1990). The fifth discipline: The art and practice of the learning organization. New York: Doubleday/Currency.

Shepard, A. (1996, September). Consultants in the newsroom. American Journalism Review, 19-23.

Shepard, A. (1997, December). Blowing up the wall. American Journalism Review, 18-27.

Shepard, A. (1998, May). The change agents. American Journalism Review, 43-49.

Shepard, A. (2000, July/August). The end of the line. American Journalism Review, 44-51.

Siebert, F. S., Peterson, W., \& Schramm, W. (1956). Four theories of the press. Urbana, Ill.: University of Illinois Press.

Smith, S. (1997). Framing from the center of the community. ASNE Change: Annual Report of the ASNE Change Committee, 3-7.SPSS 6.1 Base System User's Guide. (1994). Chicago: SPSS, Inc.

Stepp, C. S. (1995a, April). Reinventing the newsroom. American Journalism Review, 29-33.

Stepp, C. S. (1995b, October). The thrill is gone. American Journalism Review, 15-19.

Stepp, C. S. (2000, July/August). Reader friendly. American Journalism Review, 22-35. 23.

Strupp, J. (1999, December 11). Where there's a wall, there's a way. Editor $\&$ Publisher, 20- 
Sylvie, G. (1996). Departmental influences on interdepartmental cooperation in daily newspapers. Journalism \& Mass Communication Quarterly, 73 (1), 230-241.

Thames, R. (1998). Public journalism in the 1992 elections. In E. Lambeth, P., Meyer, \& E. Thorson. Assessing public journalism, 111-122. Columbia, MO: University of Missouri Press.

Thelan, G. (1997). Wrestling with change. ASNE Change: Annual Report of the ASNE Change Committee, 2.

Underwood, D. (1998, January/February). It's not just in L.A. Columbia Journalism Review, 24-26.

Weaver, D. H., \& Wilhoit, G. C. (1996). The American journalist in the 1990s: U.S. news people at the end of an era. Mahwah, NJ: Erlbaum.

Weaver, J. (1998, February 18). Newspaper change presentation and handout. School of Journalism, University of Missouri.

Whiteside, S. (1996, July-August). Web defines who an editor is. The American Editor, 4-5.

Woo, W. (1998, January/February). Why Willes is wrong. Columbia Journalism Review, 27. 